\title{
Technology shocks around the world
}

\author{
Martial Dupaigne $^{*} \quad$ Patrick Fève ${ }^{\dagger}$
}

April 7, 2005

\begin{abstract}
This article studies the effects on employment of permanent technology shocks in the major seven developed countries. The recent empirical literature that uses Structural Vector Autoregressions (SVAR) has shown that productivity shocks identified using long-run restrictions lead to a persistent and significant decline in hours worked in most industrialized countries. We argue that the technology shocks which affect labour productivity in any country spread around the world. We show that the international transmission of shocks prevents the SVAR used in the existing literature to accurately identify permanent shocks to technology, but also provides alternative identifying restrictions. Our claim that evaluations carried over using SVARs are not informative is based on both actual and artificial data. Using actual data, the sign of the measured short-run response of employment to permanent technology shocks depends on the aggregation level. Using a calibrated multi-country model to generate artificial data, we show that impulse response functions from single-country SVARs are heavily downward biased, while SVAR on zone data deliver consistent - but useless - estimates. We therefore propose alternative VAR evaluations suited to an international context. Our preferred specification, which is based on a short-run restriction, estimates consistently on impact the response of labour input to permanent technology shocks on artificial data. Using this identification scheme on actual data, we find that employment significantly increases in every G7 country following a world permanent productivity shock.
\end{abstract}

Keywords: Technology shocks, Vector Autoregressions, Business cycle models, Open economy. JEL classification: C32, E32, F41.

${ }^{*}$ GREMAQ, Université de Toulouse I, 21 allée de Brienne, F-31000 Toulouse, France. E-mail: martial.dupaigne@univ-tlse1.fr.

${ }^{\dagger}$ GREMAQ, CNRS, IDEI and Banque de France. E-mail: patrick.feve@univ-tlse1.fr. We thank Fabrice Collard, Alain Guay, Franck Portier, Harald Uhlig and Raf Wouters for their comments and suggestions. This paper has benefited from discussions during presentations at ESEM (2004, Madrid), Toulouse seminar and the "Dynamic models and monetary policy" workshop at Banque de France. Christophe Hurlin kindly provided his programs for panel unit root tests. We remain solely responsible for any error or omission. The views expressed therein are those of the authors and do not necessarily reflect those of the Banque de France. 


\section{Introduction}

This article studies the effects on employment of permanent technology shocks in the major seven developed countries. While the effects of technical progress on employment have long raised political economy issues, they have also recently been receiving a lot of emphasis in business cycle analysis. The response of employment to a technology shock belongs to the set of conditional statistics that Galí [1999] uses to discriminate between alternative business cycle models, as opposed to the unconditional statistics typically used in the RBC literature.

The challenging task in measuring the effects on inputs (including labour) of technology shocks is to measure technology itself. The conceptual object with which macroeconomists describe technology is the aggregate production function, the empirical counterpart of which is not observable. Under constant returns to scale, permanent labour-augmenting improvements in technology can however be identified. Because they do not eventually affect the optimal mix of inputs, the long-run movements in average labour productivity, which are observable, reveal those of technology. Galí [1999], Galí and Rabanal [2004] and Francis and Ramey [2005a] endorse this identifying scheme to measure the effects of permanent shocks to productivity with a Structural Vectorial Auto-Regressive (SVAR) model, using a long-run restriction à la Blanchard and Quah [1989]. These studies conclude that such technology shocks drive labour input down during several quarters in most industrialized countries. This finding contradicts standard flexible-price models, but favours sticky-price models in which output is demanddetermined in the short-run. ${ }^{1}$

In this paper, we argue that the technology shocks which affect labour productivity in any country spread around the world. We show that the international transmission of shocks first prevents the SVAR used in the existing literature to accurately identify permanent shocks to technology, but, second, provides alternative identifying restrictions.

Our claim that evaluations carried over using SVAR are not informative is based on both actual and artificial data. Using actual data, the sign of the measured short-run response of employment to permanent technology shocks depends on the aggregation level. Precisely, the following three observations are inconsistent with each other. First, SVAR evaluations carried out with single-country data suggest that employment decreases in the seven G7 countries. ${ }^{2}$ Second, permanent technology shocks have similar impacts on the G7 countries, meaning that

\footnotetext{
${ }^{1}$ Accepting this interpretation, Collard and Dellas [2003] and Francis and Ramey [2005a], among others, specify flexible-price models able to reproduce a fall in hours following a technology shock.

${ }^{2}$ Our results are similar to those obtained by Galí [1999] for a different sample period.
} 
the permanent technology shock is common to the G7 countries (or, in other words, that all country-specific shocks are temporary). Since employment does not increase in any G7 country after a common permanent shock, it should therefore not do so at the G7 level. Third, an evaluation with G7 aggregate data (i.e. total G7 employment and average productivity of labour) nevertheless reveals a significant raise in G7 employment. We label the discrepancy between the response of employment evaluated at the country and G7 level an aggregation puzzle. In the following step, we show that this puzzle can be a consequence of identification errors at the country level which disappear once data are aggregated.

Using artificial data, we test the ability of the SVAR methodology to recover the true response of employment to a permanent technology shock in a controlled experiment. We therefore follow a standard practice in econometrics to evaluate the (small-sample) properties of estimators and related test statistics. The Data Generating Process (DGP) we use is a frictionless multi-country dynamic stochastic general equilibrium (DSGE) model with a common permanent technology shock and country-specific stationary ones.

Our quantitative evaluation is similar to that undertaken in Chari, Kehoe and McGrattan [2004], Erceg, Guerrieri and Gust [2004] and Dupaigne, Fève and Matheron [2005]. These papers show, in closed-economy setups, that preference and fiscal shocks may disturb the identification of permanent technology shocks. Their common intuition is that, under decreasing returns to labour input, every shock with long-lasting detrimental effects on labour input stimulates average labour productivity, even in the medium-run. Such shocks contaminate the estimated response of labour input to permanent productivity shocks. Quantitatively, such distorsions appear to be large enough to reverse the sign of the employment response for DGPs mimicking different statistics of US data. We extend these analyses to a multi-country setup.

In an international context, foreign non-permanent shocks also induce the contamination of permanent technology shocks. Any shock that temporarily increases the productivity of a given country reduces labour input in other countries because of a wealth effect due to risk-sharing motives. The drop in hours worked raises productivity in those countries as long as capital is not fully reallocated to the most productive economy. Hence, the average productivity of labour in any country does not only reflect its own shocks, but also those of its neighbours.

A two-country model is calibrated such that one country exactly matches a set of moments that summarizes the US business cycle. The model is then used to generate artificial data. From this data, we compute IRFs of employment to the permanent technology shock using the SVAR with a long-run restriction. These estimated IRFs are thus compared to the true theoretical 
ones. We first show that the relative downward bias of the estimated response on impact is as large as $200 \%$, meaning that the SVAR evaluation does not even recover the correct sign of the 'true' response. On the contrary, an SVAR on aggregate data (i.e. data on the zone composed of all countries) reliably measures the 'true' evolution of employment. ${ }^{3}$ To the extent that the G7 collects a large enough share of the world economy, these experimental results support the aggregation puzzle uncovered empirically. From a practitioner point of view, SVAR evaluations may therefore be helpful only for economies which are either larger or more closed than the US one. $^{4}$

The set of experiments presented so far makes clear that average labour productivity does not track total factor productivity closely enough to avoid measurement problems. In a second step, we propose alternative VAR evaluations suited to an international context. These evaluations combine data from various countries in order to disentangle the different productivity shocks. Their ability to recover the 'true' dynamics of employment is tested using once again the multicountry DSGE model as a DGP. For example, replacing the growth rate of labour productivity in a single-country by the zone-average growth rate of labour productivity does not mitigate the identification problems, because the zone also receives different persistant technology shocks.

Our preferred specification uses the labour productivity differential relative to the G7 zone and a short-run restriction, namely that the permanent technology shock has a common impact on labour productivity in all countries. In the model, the labour productivity differential reacts differently to permanent shocks (which have no impact effects), transitory shocks to domestic productivity (which induce an increase in the differential) and to foreign productivity (which induces a reduction in the differential). Quantitatively, this structural VAR measures without any bias the short-run increase in hours worked that follows a permanent improvement in technology.

As just shown, a structural VAR on the growth rate of labour input and relative labour productivity with a short-run restriction nicely detects a raise in labour input. Does it also detect a decrease in hours worked? A last experiment is carried out to evaluate the discriminating power of this specification. ${ }^{5}$ The multinational model is augmented to incorporate habit persistence

\footnotetext{
${ }^{3}$ As a by-product, our experiments illustrate that the overdifferenciation issue emphasized in Christiano, Eichenbaum and Vigfusson [2003] may not matter quantitatively, since a misspecified DSVAR (structural VAR with labour input in difference) does not exhibit a large bias on an autarkic economy.

${ }^{4}$ Galí [2004] studies the Euro area as a whole, and finds that technology improvements are detrimental to employment in the Euro area, as he does on US data.

${ }^{5}$ The identification problems that Galí [1999]'s methodology suffers from can be interpreted as a lack of discriminating power. In fact, Chari et al. [2004], Erceg et al. [2004], Dupaigne et al. [2005] and the present paper all show that such SVAR may detect a fall in hours worked after a permanent productivity shocks in economies where they do
} 
in consumption. As in Wen [2001] or Francis and Ramey [2005a], the enhanced sluggishness of consumption implies a detrimental impact effect of technology shock on hours worked. In this controlled experiment as well, the average measurement bias remains very low. This illustrates the power of the labour productivity differential SVAR against a specific alternative.

Finally, when this specification is applied to actual data, the response of employment to a common productivity shock is significantly positive in all the G7 countries, during the first three years. This result is in sharp contrast with the estimated response to the permanent productivity shock identified in SVAR with long-run restriction. The two structural VARs differ in terms of identifying restriction: the first scheme identifies the shock which has the same instantaneous effect on single-country labour productivity and G7 labour productivity, while the second identifies the shock which has a long-run effect on domestic labour productivity. However, on actual data, country-specific shocks have no long-run effect on labour productivity while the common shock has; and non-permanent shocks do affect productivity differentials on impact in most countries while permanent shocks do not. Hence, both schemes aim to identify the same shock, namely the common permanent shock to G7 productivity.

The large discrepancy between these two identification schemes observed on actual data is also apparent over artificial data. In that case, it revealed the bias plaguing SVAR on singlecountry data and long-run restriction. All in all, the pieces of evidence presented in this paper do not favor the rejection of the whole class of flexible-price model in favour of sticky-price models.

Our emphasis on world shocks meets an empirical literature seeking to identify common factors in international business cycles. Recently, Stock and Watson [2003] define world shocks as those that affect GDP in all G7 countries within the same quarter. They show that this shock accounts for 30 to $90 \%$ of the $2-$ years ahead forecast error of GDP, except for Japan. Notice that our world technology shock verifies their definition. Using historical data since 1880, Bordo and Helbling [2003] find that global common shocks are the dominant influence of business cycle synchronisation across diverse exchange rate regimes. Kose, Otrok and Whiteman [2003] consider sixty countries, and show that the world factor is important in explaining fluctuations in developed and stable economies. Among others, these papers establish the large contribution of world shocks to aggregate fluctuations.

Next section presents the methodology used in Galí [1999] and Francis and Ramey [2005a], as well as the empirical response of employment evaluated at the country and G7 level. Section increase as well as in economies where they do decrease. 
2 sets up the theoretical model used as a DGP, illustrates the measurement bias and discuss how country-specific transitory shocks contaminate common permanent ones. Section 3 proposes three other SVAR specifications, tests all of them on artificial data and applies our preferred specification to actual data. Last section concludes.

\section{Technology shocks and employment in the major seven countries}

This section studies the empirical effects of permanent technology shocks on employment in the major seven countries, applying the structural VAR approach already used in Galí [1999], [2004] and [2005], Galí and Rabanal [2004], Christiano et al. [2003] and [04], Francis and Ramey [2005a], Francis and Ramey [2005b]. The existence of a unique world permanent technology shock is then established, revealing an empirical puzzle: the effects of permanent productivity shocks on employment measured through this structural VAR approach are not robust to the level of aggregation.

\subsection{An empirical methodology to measure the effects of perma- nent technology shocks}

To identify technology shocks and their effects, Galí [1999] estimates a canonical vectorial autoregressive (VAR) model over the growth rates of labour productivity, $\Delta x_{t}$, and labour input, $\Delta n_{t}$ (omitting the constant term without loss of generality):

$$
\left[\begin{array}{c}
\Delta x_{t} \\
\Delta n_{t}
\end{array}\right]=\mathbf{A}_{1}\left[\begin{array}{c}
\Delta x_{t-1} \\
\Delta n_{t-1}
\end{array}\right]+\ldots+\mathbf{A}_{p}\left[\begin{array}{c}
\Delta x_{t-p} \\
\Delta n_{t-p}
\end{array}\right]+u_{t}
$$

The error term $u_{t}$ in this expression is not serially correlated and has a variance-covariance matrix $\Omega$.

When this VAR is invertible, the growth rates of labour productivity and labour input can be expressed as a moving average (the order of which is possibly infinite) of the innovations $u$ :

$$
\left[\begin{array}{c}
\Delta x_{t} \\
\Delta n_{t}
\end{array}\right]=u_{t}+\mathbf{B}_{1} u_{t-1}+\mathbf{B}_{2} u_{t-2}+\ldots
$$

In this setup, $\mathbf{B}_{k}$ measures the $k^{\text {th }}$ period response of the endogenous variables to a unit disturbance. However, neither the disturbance $u$ nor these responses $\mathbf{B}_{k}$ can receive any structural interpretation at this point, because this vectorial moving average (VMA) representation is definitively not unique. In fact, any process

$$
\mathbf{C}_{0} v_{t}+\mathbf{C}_{1} v_{t-1}+\mathbf{C}_{2} v_{t-2}+\ldots, \text { with } E v_{t} v_{t}^{\prime}=\Psi
$$


yields the same vector of observables $\left[\Delta x_{t}^{\prime}, \Delta n_{t}^{\prime}\right]$ as soon as

$$
\left\{\begin{aligned}
\mathbf{C}_{0} v_{t} & =u_{t}, \\
\mathbf{C}_{j} \mathbf{C}_{0}^{-1} & =\mathbf{B}_{j}, \\
\mathbf{C}_{0} \Psi \mathbf{C}_{0}^{\prime} & =\Omega .
\end{aligned}\right.
$$

In a two-variables VAR, these conditions give three constraints while $\mathbf{C}_{0}$ has four elements. Structural VARs use economic theory to impose the restrictions required to compute $\mathbf{C}_{0}$ and to recover the structural shocks from the disturbance $u$.

The theoretical restriction used by Galí [1999], Galí and Rabanal [2004] and Francis and Ramey [2005a] is that improvements in technology raise the average productivity of labour, and that labour productivity is in the long-run only driven by such technology shocks. These properties arise in a large number of macroeconomic models, even though not in all of them. ${ }^{6}$ The use of average labour productivity as a proxy for technology imposes long-run identification: in the short and medium run, the stock of physical capital also affects the average productivity of labour given technology; but shocks with permanent effects on labour productivity, i.e. after capital (and any potential other input) has adjusted, are technological in nature.

Using the lag operator $L$, the growth rates of labour productivity and labour input are written as distributed lags of two orthogonal shocks, $\left\{\epsilon_{t}^{z}\right\}$ and $\left\{\epsilon_{t}^{m}\right\}$ of identity variance-covariance matrix:

$$
\left[\begin{array}{l}
\Delta x_{t} \\
\Delta n_{t}
\end{array}\right]=\left[\begin{array}{ll}
C_{11}(L) & C_{12}(L) \\
C_{21}(L) & C_{22}(L)
\end{array}\right]\left[\begin{array}{c}
\epsilon_{t}^{z} \\
\epsilon_{t}^{m}
\end{array}\right]
$$

The identifying restriction $C_{12}(1)=0$ implies that the second shock, $\left\{\epsilon_{t}^{m}\right\}$, does not have any long run impact on productivity. Hence, the first shock, $\left\{\epsilon_{t}^{z}\right\}$, is the only one having permanent effects on labour productivity, and can be interpreted as a permanent technology shock.

We use this methodology to evaluate the impact response of employment to the permanent technology shock in the G7 countries. For the sake of comparison, we measure output and labour input by GDP and civilian employment per capita. ${ }^{7}$ National as well as aggregated data $^{8}$ are available in the OECD Main Economic Indicators from 1978:1 to 2002:4. The results of ADF and KPSS unit root tests, reported in tables 7 to 9 (in appendix) and further discussed later on, suggest that log labour productivity and log employment are difference stationary and that the VAR model (1) underlying the VMA representation (2) is stationary. The number of

\footnotetext{
${ }^{6}$ Endogenous growth models are obvious examples of setups in which non-technology shocks (here, any shock) have long-run effects on labor productivity. Alternatively, Uhlig [2004] emphasizes permanent changes in the capital tax rate or changing attitude towards the workplace.

${ }^{7}$ Galí and Rabanal [2004] compare the results of evaluations undertaken for different indicators of output and labour input.

${ }^{8}$ For example, the G7 employment number simply sums single-country employment figures.
} 
lags for each country, selected according to an Akaike information criterion, appears in Table 13.

Table 1 displays the estimated impact responses of productivity and employment to the permanent productivity shock, in each country and at the aggregated level. For each country, point estimates $\hat{C}_{11}(0)$ and $\hat{C}_{21}(0)$ are displayed in the first two columns. The last column reports the results of Montecarlo experiments over 500 drawings in the distribution of reducedform VAR errors. It measures the probability that the employment decreases on impact after a shock that has a positive permanent impact on productivity.

Table 1: Impact response to a permanent productivity shock

\begin{tabular}{lrrr}
\hline \hline & productivity & \multicolumn{2}{c}{ employment } \\
\cline { 3 - 4 } country & point estimate & point estimate & $\%$ of distribution $\leq 0$ \\
\hline United States & 0.407 & -0.084 & 69.27 \\
Canada & 0.378 & -0.301 & 99.29 \\
United Kingdom & 0.388 & -0.387 & 100 \\
Germany & 0.911 & -0.176 & 96.86 \\
France & 0.329 & -0.097 & 88.61 \\
Italy & 0.835 & -0.443 & 100 \\
Japan & 0.751 & -0.092 & 93.18 \\
G7-weighted sum & - & -0.191 & - \\
\hline G7 & 0.368 & 0.104 & 2.26 \\
\hline \hline
\end{tabular}

Note: VAR estimated on actual data, with the number of lags in Table 13. The estimated density function over 500 simulations is smoothed with a Gaussian kernel. Sample period: 1978:1-2003:4. Source: OECD Main Economic Indicators.

The seven first rows of Table 1 shows that the impact response of employment is negative in all the G7 countries, while that of productivity is naturally positive. In four of these countries (Canada, United Kingdom, Germany and Italy), the null hypothesis that employment decreases on impact is not rejected at the 5\% level. These findings support Galí [1999]'s evidence: employment does significantly decrease on impact in several G7 countries, ${ }^{9}$ and does not increase in any.

Hence, under the assumption that the permanent technology shock is common to the major seven countries, the G7 employment impact response is expected to be negative as well. The eighth row computes the point estimate of the impact response of G7 employment by aggregation

\footnotetext{
${ }^{9}$ Using quarterly employment data and annual hours worked data from the OECD Labor Force Statistics respectively, both Galí [1999] and Galí [2005] find that labour input decreases after a permanent technology shock in all G7 countries but Japan.
} 
of the seven national point estimates. ${ }^{10}$ Unsurprisingly, this number is negative.

Finally, the ninth row of Table 1 reports the counterpart of the seven single-country exercises, but on G7 aggregated data available in the OECD database. This exercise provides an alternative to the previous one to evaluate the aggregated effects of a technology shock. Over this data set, a permanent improvement in productivity actually raises employment. As such, this would mean that a permanent improvement in technology reduces instantaneously employment in every G7 country, but at the same time stimulates the G7 aggregate employment. We label this observation the aggregation puzzle.

Next, empirical evidence is provided that the permanent shocks to productivity are global (or at least common to the G7 countries). We also investigate whether the literature that criticizes structural VARs may account for this puzzle. Our preferred explanation for this puzzle, detailed in the third section, is that the estimated response of G7 employment can be trusted while national responses - hence the aggregation of them - cannot.

Figure 1 provides a last illustration of the aggregation puzzle which supports this view. Figure 1 plots the distribution of the impact response of G7 employment to the permanent shock to G7 productivity, as well as the impact response obtained through aggregation of singlecountry responses (grey solid line). The probability that the aggregation of single-country responses equals the response estimated over aggregate data is 0 (The probability that the response estimated over aggregate data exceeds the aggregation of single-country responses is $1)$.

\subsection{An aggregation puzzle}

The aggregation of single-country effects, undertaken in Table 1, implicitly follows Stock and Watson [2003] and assumes that the major seven countries are hit by a common permanent technology shock, i.e. a shock which affects simultaneously all economies. This assumption is tested by comparing the effects of permanent technology shocks on labour productivity in different countries. Specifically, we compute the impact of permanent technology shock on productivity differentials vis-à-vis the United States, and vis-à-vis the G7, through the following SVARs: ${ }^{11}$

$$
\left[\begin{array}{c}
\Delta x_{t} \\
x_{t}-x_{t}^{\mathrm{US}}
\end{array}\right]=\left[\begin{array}{ll}
\tilde{C}_{11}(L) & \tilde{C}_{12}(L) \\
\tilde{C}_{21}(L) & \tilde{C}_{22}(L)
\end{array}\right] \epsilon_{t}, \text { with } \tilde{C}_{12}(1)=0, \text { and }
$$

\footnotetext{
${ }^{10}$ Labeling $\hat{C}_{21}^{i}(0)$ the point estimate of the impact response of employment in country $i$ and $\pi_{i}$ its relative population, this number is precisely $\log \left\{\sum_{i}\left[\pi_{i} \exp \left(\hat{C}_{21}^{i}(0)\right)\right]\right\}$.

${ }^{11}$ The stationarity of these productivity differentials is discussed in Appendix.
} 
Figure 1: Impact response of employment in the G7

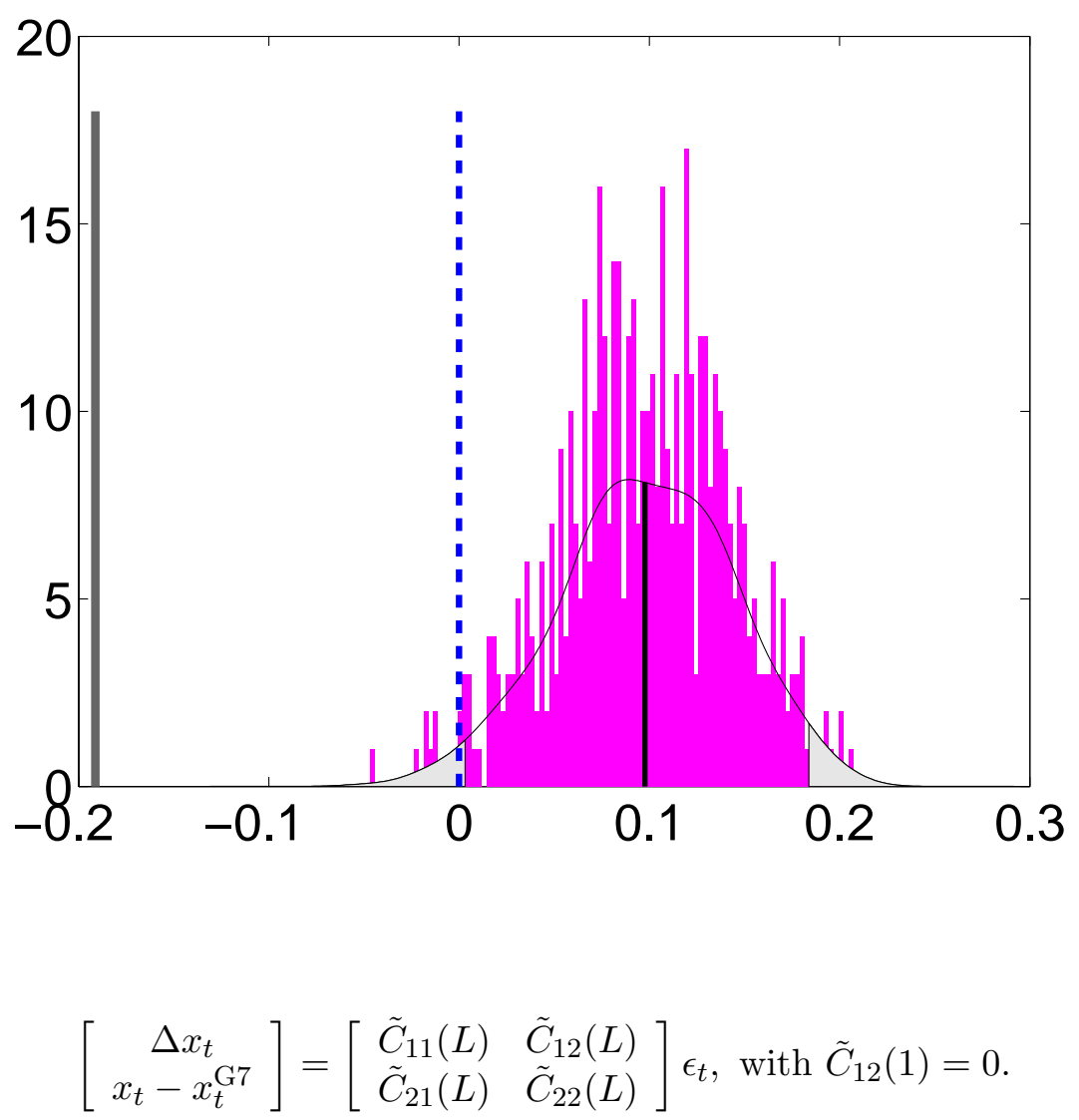

The first (respectively last) two columns of Table 2 report the estimated impact of a permanent shock in each country to the productivity differential of that country with respect to the US (respectively G7). The first column displays the point estimate of $\tilde{C}_{21}(0)$, while the second one computes the percentage of the distribution for which the productivity differential increases. It is meant to test whether the estimated effect on relative productivity of permanent shocks statistically differs from zero. If not, the permanent shock hits all the G7 countries, at the same time. Hence, the aggregation results in Table 1 are meaningful.

For example, the third line of Table 2 reads as follows: according to specification (3), the shock which has a permanent impact on productivity in the United Kingdom raises labour productivity in the US more than in the United Kingdom, ${ }^{12}$ by around $.2 \%$; Monte carlo replications show that the United Kingdom labour productivity differential vis-à-vis the US decreases for a third of observations, while it increases for two third of observations.

The point estimates $\tilde{C}_{21}(0)$ show that permanent shocks to productivity increase the productivity differential with respect to the US for three countries, and reduces it for the other three.

\footnotetext{
${ }^{12}$ Each permanent productivity shock raises national labour productivity on impact, as shown in the last column of Table 1 .
} 
Table 2: Impact response of relative labour productivity to a permanent productivity shock

\begin{tabular}{lrrrrr}
\hline \hline & \multicolumn{2}{c}{ relative to the US } & & \multicolumn{2}{c}{ relative to the G7 } \\
\cline { 2 - 3 } country & estimate & \% of obs. $\geq 0$ & & estimate & \% of obs. $\geq 0$ \\
\hline United States & - & - & & 0.090 & 73.19 \\
Canada & -0.683 & 20.56 & & -0.101 & 44.93 \\
United Kingdom & -0.181 & 33.32 & & 0.398 & 96.91 \\
Germany & 0.386 & 76.43 & & -0.265 & 27.68 \\
France & 0.059 & 27.73 & & -0.246 & 54.82 \\
Italy & 0.181 & 61.90 & & -0.492 & 16.99 \\
Japan & -0.224 & 30.36 & & -0.331 & 20.57 \\
\hline \hline
\end{tabular}

Note: VAR estimated on actual data, with the number of lags in Table 13. The estimated density function over 500 simulations is smoothed with a Gaussian kernel. Sample period: 1978:1-2003:4. Source: OECD Main Economic Indicators.

However, the nullity of the six impact responses can not be rejected at conventional levels. The replication of this exercise for the productivity differential vis-à-vis the G7 confirms the previous findings: at the $5 \%$ level, a bilateral test on the estimated impact on relative productivity does not reject the null hypothesis in any country (0 does not belong to one of the $2.5 \%$ tails). At the $10 \%$ level, it is only rejected for the United Kingdom. ${ }^{13}$

The permanent productivity shock that hits any G7 country not only improves instantaneously average labour productivity in this country, but also in the six others. ${ }^{14}$ This shock increases productivity simultaneously and proportionally in all countries.

Table 3 reports the same statistics for the impact response of labour productivity differential to the non-permanent shocks, $\tilde{C}_{22}(0)$. As opposed to permanent shocks, the instantaneous effects of non-permanent shocks differ across countries. At the $10 \%$ level, the null hypothesis of symmetry is rejected (i.e. 0 does not belong to the $5 \%$ tails) in all countries but Canada when national productivities are compared to the US one (two first columns); in all countries but France when productivity is compared to the G7 one (two last columns). At the $5 \%$ level, the invariance of productivity differentials cannot be rejected for these two countries, but is strongly reject for United Kingdom, Germany, Italy, Japan and, when relevant, the United States. The results in Table 2 and 3 support the existence of a common permanent technology shock in the G7 alongside country-specific non-permanent shocks.

\footnotetext{
${ }^{13}$ Alternative VARs $\left[\Delta x_{t}^{\prime}, \Delta n_{t}^{\prime},\left(x_{t}-x_{t}^{\mathrm{US}}\right)^{\prime}\right]$ and $\left[\Delta x_{t}^{\prime}, \Delta n_{t}^{\prime},\left(x_{t}-x_{t}^{\mathrm{G} 7}\right)^{\prime}\right]$ with long run restrictions, which encompass specification (2), deliver quantitative results very close to those presented in Table 2.

${ }^{14}$ This property is stronger than cointegration of labour productivity in the G7. It not only implies that labour productivities share a stochastic trend, but also that this permanent shock affects the different countries at the same date.
} 
Table 3: Impact response of relative labour productivity to a non-permanent shock

\begin{tabular}{lrrrrr}
\hline \hline & \multicolumn{2}{c}{ relative to the US } & & \multicolumn{2}{c}{ relative to the G7 } \\
\cline { 2 - 3 } country & estimate & \% of obs. $\geq 0$ & & estimate & \% of obs. $\geq 0$ \\
\hline United States & - & - & & 0.367 & 100 \\
Canada & -0.033 & 77.18 & & 0.580 & 96.96 \\
United Kingdom & 0.700 & 99.77 & & 0.514 & 99.83 \\
Germany & 0.907 & 99.74 & & 0.645 & 99.92 \\
France & 0.588 & 95.76 & & -0.364 & 79.09 \\
Italy & 1.010 & 99.80 & & 0.696 & 99.83 \\
Japan & 0.975 & 100 & & 0.673 & 99.87 \\
\hline \hline
\end{tabular}

Note: VAR estimated on actual data, with the number of lags in Table 13. The estimated density function over 500 simulations is smoothed with a Gaussian kernel. Sample period: 1978:1-2003:4. Source: OECD Main Economic Indicators.

The G7 countries being simultaneously hit by the same permanent technology shocks, the weighted average of the single-country employment impact response should therefore measure the response of G7 employment to the common permanent technology shock. But this weighted average significantly differs, as shown in Figure 1, from the response directly computed over aggregate data.

\subsection{Possible explanations for the aggregation puzzle}

Here we investigate whether the literature that has followed Galí [1999] has raised issues able to explain the aggregation puzzle we have uncovered.

Overdifferenciation Christiano et al. [2003] claim that the VAR on growth rates of labour productivity and labour input is misspecified on US data, because US hours worked per capita are stationary and not difference stationary. Overdifferencing labour input induces a bias on the estimated response of employment. Christiano et al. [2003] estimate a VAR on the growth rate of labour productivity and the log of labour input. They find that hours worked actually increase after a permanent shock to productivity. ${ }^{15}$

Regarding the aggregation puzzle, the overdifferencing argument holds if national employment data are stationary - inducing a bias in the single-country experiments - while G7 employment data are difference-stationary; or if single-country data are difference-stationary and G7 employment are not - meaning that the bias lies in our last experiment.

\footnotetext{
${ }^{15}$ Using model-based experiments, Chari et al. [2004] however show that a structural VAR with employment in level may also deliver a positive bias; that is, estimated responses of employment can exceed te true ones.
} 
Tables 7 to 9 , in appendix, report the results of two sets of unit root tests applied on employment data. These results do not provide evidence that single-country and aggregated employment data have different integration orders. In fact, any weighted sum of unit root process is a unit root process.

Lags Chari et al. [2004] argue that the autoregressive representation of a business cycle model fitted to US data is not well approximated with a small number of lags, regardless whether the log-level or growth rate of labor input is considered. They show that at least one hundred lags are required to approximate well the VAR process. Quantitatively, the induced bias is large enough to reverse the sign of the estimated response of employment for typical number of lags (four to ten) in the difference specification. Furthermore, standard lag length tests do not detect the need for more lags in the level specification.

Here, the argument may apply along two lines. First, the number of lags selected in the different exercises need not be the same (it is not, see Table 13); hence, the number of lags selected on single-country data may provide a better approximation of the true process of the underlying variables than the number of lags selected on aggregate data, or vice versa. To account for this possibility, we run the same exercises with the maximum number of lags detected in the first step (twelve) applied homogeneously to all datasets. The probability that the impact response evaluated on aggregated data exceeds the weighted average of single-country point estimates remains larger than $99.99 \%$.

Second, the VAR process underlying single-country data and aggregate data may not require the same number of lags to be well approximated. None of these processes being observable, this point calls for the specification of national and multinational business cycle models and for the study of their recursive representation.

Missing variables To control for a potential omitted-variable bias, Erceg et al. [2004] estimate on artificial data a larger VAR, which includes the ratio of consumption and investment to output. They show that the sign of the estimated response remains unchanged, while the precision of estimation is improved. On actual US data, Galí [1999] and Christiano et al. [2003] obtain similar results. Recently, Francis, Owyang and Theodrou [2004] estimates four-variable SVAR (including labor productivity, employment, short-term nominal interest rate and inflation rate) for the G7 countries. The impact response of employment to a permanent technology shock remains negative in all countries but France. Their findings suggest that the results in Table 1 do not suffer from severe omitted-variable bias. 


\section{The identification of permanent technology shocks through long-run restrictions}

To measure the reliability of the SVAR approach, we construct an artificial multi-country economy hit by permanent productivity shocks and transitory ones. This model economy is used as a DGP to simulate artificial data over which the SVAR is estimated, as do Chari et al. [2004], Erceg et al. [2004] or Uhlig [2004]. The SVAR evaluation is first performed over artificial data for a single country; then over artificial aggregate data. In both cases, the estimated response of employment to the permanent productivity shock are compared to the theoretical effect, known from the model propagation mechanism.

\subsection{The theoretical model}

We consider a flexible-price dynamic general equilibrium model à la Baxter and Crucini [1993] or Backus, Kehoe and Kydland [1995]. The world is composed by $n$ countries, the first one being labeled as 'home country'. These countries are symmetrical, except in terms of population. A fraction $\pi_{i}$ of the world population lives in country $i$. These shares are constant over time and $\sum_{i=1}^{n} \pi_{i}=1$. All variables are expressed per capita.

\section{Preferences}

Households in country $i$ are endowed with one unit of time. They choose consumption and leisure plans, $\left\{C_{i, t}\right\}_{t=0,+\infty}$ and $\left\{L_{i, t}\right\}_{t=0,+\infty}$, so as to maximize their expected lifetime utility

$$
E_{0} \sum_{t=0}^{+\infty} \beta^{t}\left[\log C_{i, t}+\vartheta \log L_{i, t}\right], i=1, \ldots, n \text { with } 0<\beta<1 \text { and } \vartheta>0
$$

subject to a sequence of budget and time constraints.

\section{Technology}

All firms have access to a constant-returns-to scale technology to produce a unique good. Respectively denoting $Y_{i, t}, K_{i, t}$ and $N_{i, t}$ the output, the capital input and labor input in country $i$ at date $t$, the production function writes

$$
Y_{i, t}=\left(\Gamma_{i, t} N_{i, t}\right)^{\alpha} K_{i, t}^{1-\alpha}, i=1, \ldots, n
$$

with $0<\alpha<1$. In this expression, $\Gamma_{i, t}$ represents the stochastic labor-augmenting technical change/progress affecting country $i$. 
Labor is not mobile across countries. In each country, the following constraint holds

$$
1-L_{i, t}-N_{i, t} \geq 0, i=1, \ldots, n \text {. }
$$

Capital input is mobile across countries but subject to adjustment costs (which vanish along the stochastic balanced growth path). Hence, the accumulation of national capital stock follows $K_{i, t+1} \leq(1-\delta) K_{i, t}+I_{i, t}-\frac{\varphi}{2}\left(\frac{I_{i, t}}{K_{i, t}}-\frac{\bar{a}-1+\delta}{\bar{a}}\right)^{2} K_{i, t}, i=1, \ldots, n$ with $0<\delta<1$ and $\varphi \geq 0$

\section{Markets}

The final good is internationally mobile. The world resource constraint writes

$$
\sum_{i=1}^{n}\left(Y_{i, t}-C_{i, t}-I_{i, t}\right) \geq 0 .
$$

Individual agents have access to a complete set of markets for state-contingent assets. The equilibrium of this model economy is equivalent to the solution of the following social planner program:

$$
\begin{aligned}
\max _{\left\{C_{i, t}, I_{i, t}, L_{i, t}, N_{i, t}\right\}_{t=0,+\infty}} & \mathcal{L}=E_{0} \sum_{t=0}^{+\infty} \beta^{t}\left\{\sum_{i=1}^{n} \pi_{i}\left[\log C_{i, t}+\vartheta \log L_{i, t}\right]\right. \\
& +\sum_{i=1}^{n} \Lambda_{i, t} \pi_{i}\left[(1-\delta) K_{i, t}+I_{i, t}-\frac{\varphi}{2}\left(\frac{I_{i, t}}{K_{i, t}}-\frac{\bar{a}-1+\delta}{\bar{a}}\right)^{2} K_{i, t}-K_{i, t+1}\right] \\
& +\sum_{i=1}^{n} W_{i, t} \pi_{i}\left(1-L_{i, t}-N_{i, t}\right) \\
& \left.+P_{t}\left[\sum_{i=1}^{n} \pi_{i}\left(Y_{i, t}-C_{i, t}-I_{i, t}\right)\right]\right\}
\end{aligned}
$$

with the Lagrange multipliers $\Lambda_{i, t} \geq 0 \forall i, t, W_{i, t} \geq 0 \forall i, t$ and $P_{t} \geq 0 \forall t$, given initial conditions on capital stock. The usual transversality conditions apply.

\section{Shocks}

The structural VAR methodology described in 1.1 emphasizes permanent productivity shocks. When hit by productivity shocks integrated of order one, closed economies display a stochastic balanced growth path. A stationary transformation of such economies converge towards an unique steady-state. This is no longer the case in a multi-country setting if countries are affected by independent productivity shocks. The stationarity of equilibrium ratios requires that national levels of total factor productivity share a common stochastic trend. In each country, output, labour productivity, consumption (and a number of other variables) follow the same stochastic trend (see for example King, Plosser, Stock and Watson [1991] for an empirical 
work based on this restriction). Under complete markets, the marginal utility of consumption is proportional across country, which implies that consumption flows in all countries share a common trend. Hence, national labour productivities need to be cointegrated. ${ }^{16}$

As in Erceg et al. [2004], we decompose Total Factor Productivity (TFP) into two components: a random-walk with drift, and a stationary autoregressive process of order one. Specifically, we assume that national TFPs processes are as follow:

$$
\left\{\begin{aligned}
\Gamma_{i, t} & =A_{t} \exp e_{i, t}, \text { where } e_{i, t}=\rho e_{i, t-1}+\varepsilon_{i, t}, i=1, \ldots, n \\
A_{t} & =A_{t-1} \exp a_{t}
\end{aligned}\right.
$$

with $0 \leq \rho<1,\left\{a_{t}\right\}$ an iid process of mean $\bar{a}>1$ and variance $\sigma_{a}^{2}$, and $\left\{\varepsilon_{i, t}\right\}$ a collection of $n$ white noises of variance $\sigma_{\varepsilon_{i}}^{2}$. Hence, $n$ transitory sovereign shocks to TFP coexist in this model with one permanent world TFP shock.

We emphasize here the distinction between permanent and transitory shocks, more than a distinction between productivity and non-productivity shocks. In a closed economy, permanent and transitory technology shocks exhibit the same covariation with employment, such that no room is left for contamination in the identification of permanent technology shocks (see section 2.4). Conversely, the international transmission of stationary foreign shocks alter the ability of SVARs to consistently identify the effects of permanent productivity shocks. In fact, a foreign stationary technology shock, a domestic preference shock and a domestic fiscal shock all share the same effects on the domestic economy in the short-run, namely a decrease in employment and a rise in average labor productivity.

Output in efficiency units is defined as $y_{i, t}=\frac{Y_{i, t}}{A_{t}}$, and the same transformation is applied to exnditures. Intensive physical capital of country $i$ writes $k_{i, t}=\frac{K_{i, t}}{A_{t-1}}$. This transformed multi-country economy exhibits a unique steady-state.

\subsection{Calibration and propagation of shocks}

The quantitative experiments presented in the following compare the predictions of the model for the 'home' economy with United States actual data. Values of the deep parameters are calibrated to replicate features of the US economy.

We assume that countries are symmetrical, i.e. that the functional forms and parameters describing preferences and technology are identical in all countries. Two characteristics differ

\footnotetext{
${ }^{16}$ In Appendix A and B, we test the stationarity of labour productivity differentials vis-à-vis the USA and the G7, which impose a cointegrating vector equal to $(1,-1)$ in productivity pairs. Univariate unit root tests do not deliver clear-cut evidence, but their lack of power is well-known. We thus implement panel unit root tests which are more powerful (see Levin, Lin and Chu [2002]). These tests reject unit root, and therefore support the stationarity of productivity differentials.
} 
across country: their size, and the variance of their country-specific stationary technology shock. To remain parsimonious in terms of parameters, we consider the special case of two countries (i.e. $n=2)$.

We partition the model parameters into two groups. The first group is composed of $\pi_{1}, \alpha$, $\beta, \delta$ and $\bar{a}$ which are calibrated prior to the estimation of a second group of parameters.

The empirical counterpart of the 'world' economy (that is the collection of national economies) we consider is the G7, the group of major seven industrialized countries. Therefore, we set $\pi_{1}$ to $40 \%$, which is the average share of US population (aged 15 to 64 ) in the G7 one. Table 4 displays all parameter values.

Table 4: Parameter values

\begin{tabular}{cccc}
\hline \hline \multicolumn{2}{c}{ Calibrated } & \multicolumn{2}{c}{ Estimated } \\
Parameter & Value & Parameter & Value \\
\hline$\pi_{1}$ & .4 & $\varphi$ & 2.96 \\
$\alpha$ & .6 & $\sigma_{a}$ & .010 \\
$\beta$ & .9895 & $\sigma_{\varepsilon_{1}}$ & .003 \\
$\delta$ & .025 & $\sigma_{\varepsilon_{2}}$ & .028 \\
$\bar{a}$ & 1.004 & $\rho$ & .963 \\
\hline \hline
\end{tabular}

The elasticity of output to the labor input $\alpha$ equals 0.6 , the average share of labor income to output. The psychological discount rate $\beta$ is chosen such that the steady-state annual return to capital equals $6 \%$. The depreciation rate of physical capital $\delta$ and the average growth rate of total factor productivity $\bar{a}$ are respectively set equal to, 0.025 and 1.004 (Cooley and Prescott [1995]). The value of $\vartheta$ in the utility function is chosen such that households allocate $20 \%$ of their time to market activities.

The second group of parameters includes the capital adjustment cost parameter, $\varphi$, together with the coefficients governing the autoregressive processes of the country-specific components of productivity $\sigma_{a}, \sigma_{\varepsilon_{1}}$ and $\sigma_{\varepsilon_{2}}$. These parameters are estimated using the method of moments.

The second order moments we use, displayed in Table 5, are computed on HP-filtered data: the standard deviation of cyclical output $\sigma_{\hat{Y^{h}}}$, labour input $\sigma_{\hat{N}^{h}}$ and investment $\sigma_{\hat{I}^{h}}$; the correlation between labour productivity and labour input $\operatorname{corr}\left(\hat{N}^{h}, \widehat{Y^{h} / N^{h}}\right)$; and the first order autocorrelation of labour productivity $\rho_{Y^{h / N^{h}}}$. Since we do not impose any over-identifying restriction, the model exactly matches our set of second-order moments. ${ }^{17}$

\footnotetext{
${ }^{17}$ This set of moments includes stylized facts on the labor market that standard RBC models have tremendous difficulty to reproduce.
} 
Table 5: Historical moments

\begin{tabular}{ccccc}
\hline \hline$\sigma_{\hat{Y^{h}}}$ & $\sigma_{\hat{N^{h}}}$ & $\sigma_{\hat{I^{h}}}$ & $\operatorname{corr}\left(\hat{N}^{h}, \widehat{Y^{h} / N^{h}}\right)$ & $\rho_{\widehat{Y^{h} / N^{h}}}$ \\
\hline .0156 & .0178 & .0411 & -.4863 & .7282 \\
\hline \hline
\end{tabular}

Source: US data from the National Income and Product Accounts. $Y^{h}$ stands for per capita GDP; $N^{h}$ for per capita hours worked in the nonfarm business sector; $I^{h}$ for per capita non-residential investment plus consumption in durable goods. Sample period 1955:1 to 2002:4.

For parameter values in Table 4, we solve numerically for the equilibrium of the model economy. The solutions for labour input, $n^{1}$, and labour productivity, $x^{1}$, of the home economy respectively write

$$
\left\{\begin{array}{l}
n_{t}^{1}=N(L) \times\left[a_{t}, \varepsilon_{1, t}, \varepsilon_{2, t}\right]^{\prime} \\
x_{t}^{1}=X(L) \times\left[a_{t}, \varepsilon_{1, t}, \varepsilon_{2, t}\right]^{\prime}
\end{array}\right.
$$

Hence, $N_{i}(\cdot)$ and $X_{i}(\cdot)$ describe the response of labour input and labour productivity, respectively, to shock $i, i=\left\{a_{t}, \varepsilon_{1, t}, \varepsilon_{2, t}\right\}$. In what follows, we will specially focus on the impact response of employment to the world technology shock, $N_{1}(0)$.

Figure 2 displays the response of home employment and labour productivity to the three shocks hitting the model economy. The left panel portrays a one standard-deviation improvement in the common component of TFP. This permanent technology improvement raises instantaneoulsy domestic labour productivity as well as the steady-state level of home capital. The average productivity of labour further increases as capital is accumulated. ${ }^{18}$ The corresponding increase in the shadow price of capital induces households to supply more labour. Home employment does increase by approximately $.5 \%$ and returns monotonically to steady state.

Figure 2: Theoretical impulse response functions of home employment and labour productivity
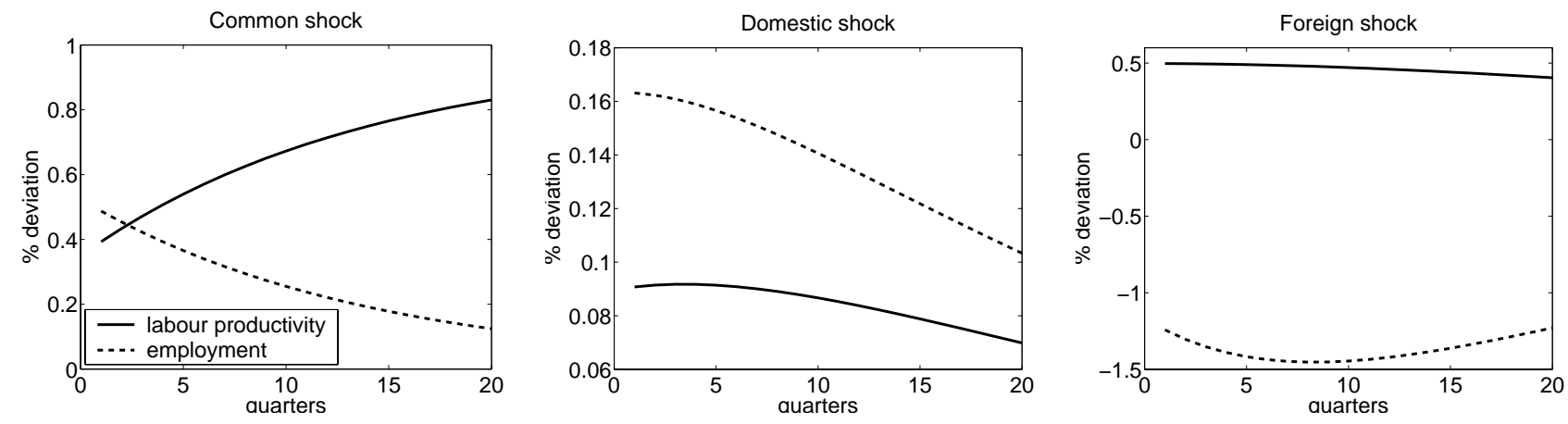

\footnotetext{
${ }^{18}$ The response of labour productivity for long horizons tends to $1 / \alpha$ the increase in TFP.
} 
The middle panel shows the effects of the domestic stationary productivity shock. Home employment increases on impact due to intertemporal substitution, marginal returns of production factors being temporarily high. Nevertheless, labour productivity slightly increases after impact. International reallocation of capital is taking place under TFP differences, but is slowed down by the capital adjustment costs. ${ }^{19}$

Finally, the effects on home economy of the foreign stationary TFP shock are displayed in the right panel. In the home country, technology is not affected (at any horizon). However, in the presence of complete asset markets, asset portfolio diversification ensures risk sharing. Households living and working in the home country own shares of foreign firms. The value of these shares, equal to the expected discounted revenues of capital, increases after the positive foreign productivity shock. Getting wealthier, domestic households supply less labour and home employment decreases by more than $1 \%$ on impact. At the date of the shock, this raises the capital-labor ratio and average productivity of labour: the impact response of labour productivity equals $(\alpha-1)$ times the impact response of employment. Over time, capital gets transferred to the foreign economy, which further depresses employment.

\subsection{Testing the measurement device}

We use the model to simulate artificial data, over which is replicated the structural VAR employed in Galí [1999] and Francis and Ramey [2005a], among others. This procedure relies on a long-run restriction verified in our data generating process, namely that only one shock has a permanent effect on labour productivity. In the model economy, this permanent shock affects the component to TFP that is common to both countries.

Based on random realizations of $a, \varepsilon_{1}$ and $\varepsilon_{2}$, we compute $S$ equilibrium paths for the growth rates of home employment and labour productivity, $\Delta x_{t}^{1, k}$ and $\Delta n_{t}^{1, k}, k=1, \ldots, S$. For each draw, we estimate the following VAR model:

$$
\left[\begin{array}{c}
\Delta x_{t}^{1, k} \\
\Delta n_{t}^{1, k}
\end{array}\right]=B_{1} \times\left[\begin{array}{c}
\Delta x_{t-1}^{1, k} \\
\Delta n_{t-1}^{1, k}
\end{array}\right]+\ldots+B_{p} \times\left[\begin{array}{c}
\Delta x_{t-p}^{1, k} \\
\Delta n_{t-p}^{1, k}
\end{array}\right]+u_{t}^{k}
$$

with a number of lags $p$ chosen according to Akaike's information criterion.

From the estimated VAR specification (7), we compute the moving-average representation analog to (2),

$$
\left[\begin{array}{c}
\Delta x_{t}^{1, k} \\
\Delta n_{t}^{1, k}
\end{array}\right]=\left[\begin{array}{ll}
C_{11}^{k}(L) & C_{12}^{k}(L) \\
C_{21}^{k}(L) & C_{22}^{k}(L)
\end{array}\right] \epsilon_{t}^{k}
$$

\footnotetext{
${ }^{19}$ Backus, Kehoe and Kydland [1992] show that, absent any friction, national capital stocks would unrealistically swing in response to shocks.
} 
imposing the long-run restriction $C_{12}^{k}(1)=0$.

The SVAR methodology reliably measures the effects of a permanent technology shock on employment if the distribution of estimated responses inferred from $C^{k}(L)$ is close from the 'true' model response, obtained through the matrix polynomial $N(L)$. In Figure 3, we evaluate the distance between model and SVAR response on impact and over time.

The left panel plots the mean SVAR impulse response function of employment (plain line) and two standard-error confidence interval (grey area), together with the model impulse response function (dashed line). If $S$ draws of the model equilibrium paths for labor input and productivity were available to an applied researcher, she would mistakingly reject the null hypothesis that these data have been generated by the model. This quantitatively shows that the SVAR procedure does not recover accurately the model VMA representation (6). Qualitatively, this applied researcher would conclude that labor input decreases during nearly ten periods after the permanent productivity shock, while it does increase over this horizon in the underlying model.

Figure 3: Estimated response of employment to the permanent productivity shock
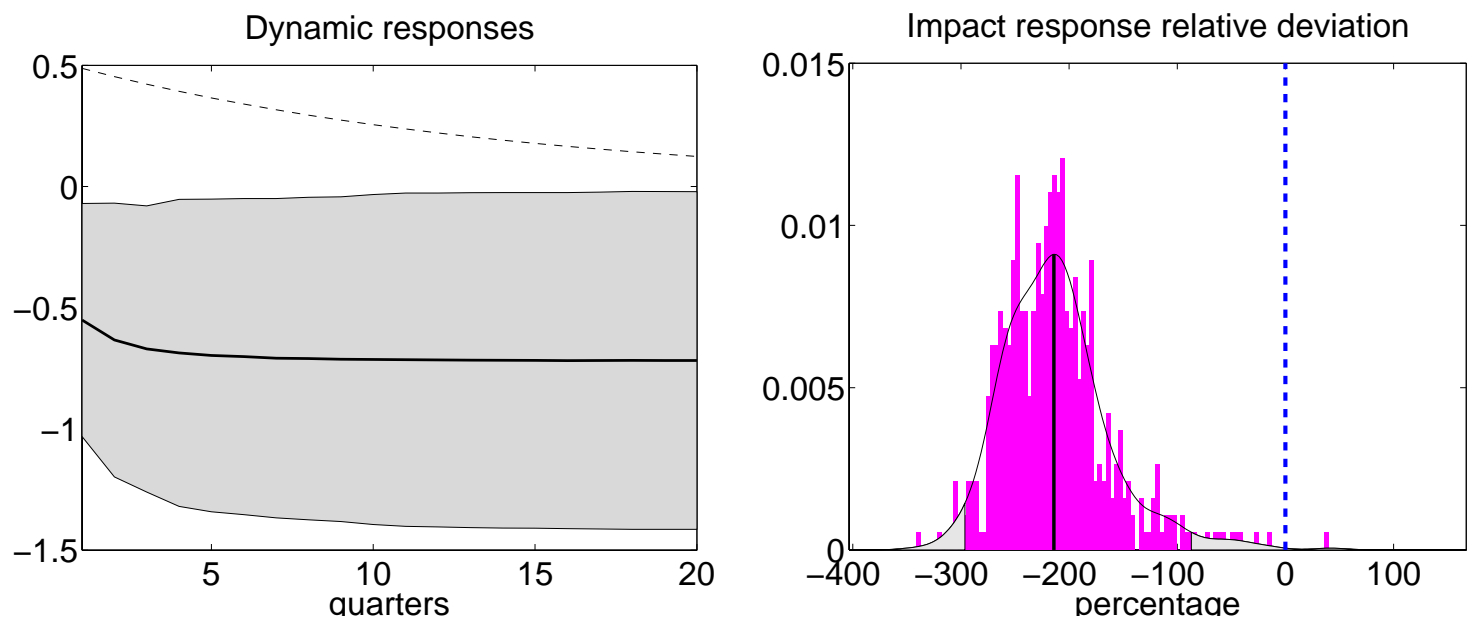

Note: VAR estimated on data generated by the international model with parameter values described in Table 4 ( $S=500$ simulations of 100 observations long samples), yielding the VMA representation (8).

The right panel focuses on the impact employment response. It displays the estimated distribution of the SVAR relative deviation from the true response, $\left\{\hat{C}_{21}^{k}(0) / N_{1}(0)-1\right\}_{k=1, \ldots, S}$. The plain line is the probability density function, smoothed with a gaussian kernel, with the mean and $2.5 \%$ tails (grey areas) reported. According to that pseudo-empirical distribution function, $99.76 \%$ of observations underestimate $N_{1}(0)$ while only $0.24 \%$ overestimate it. In absolute terms, the mean impact error is as high as $200 \%$. 
As in Chari et al. [2004] and Erceg et al. [2004], we find that the structural VAR methodology with a long-run identification restriction delivers biased estimates of the effects on employment of a permanent productivity shock. ${ }^{20}$ Specifically, this methodology detects detrimental effects on employment of technology improvements in artificial worlds where they are present (see Galí [1999] or Galí and Rabanal [2004]) as well as in worlds where they are not (like the one we study). As such, this empirical approach does not provides any reliable information on the underlying structure of the economy. Furthermore, the simple model used here as an artificial economy belongs to the very class of models that the methodology is used to take a stand on. Being calibrated on key moments of US data, the model should not be dismissed at face value, despite its evident simplicity and over-stylized nature.

\subsection{Contamination}

The identification problems evidenced in the previous section arise from the long-run behaviour of labour productivity. Home labour productivity is affected by the two country-specific stationary shocks as well as by the common permanent shock. Although the common TFP shock is the only one with permanent effects on the average productivity of domestic labour input, the effects of the two stationary shocks are indeed very long-lasting (see Figure 2). The identifying restriction imposed in the structural VAR that only one shock may have long-run effects on labour productivity fails to disentangle the effects of the three shocks. In fact, the SVAR estimated response combines the response of employment to the three structural shocks present in the model economy, with weights increasing in their variance.

Next, we illustrate these identification problems by varying the size of the three shocks hitting the economy. To maximize difference, we completely shut down one of the countryspecific stationary shocks to productivity: first the domestic one (Figure 4), next the foreign one (Figure 5), the volatility of the common shock being kept unchanged.

In a world without foreign shocks, the left panel of Figure 4 shows that the SVAR nicely estimates the theoretical response of employment at all horizons. ${ }^{21}$ The estimated value is both considerably less biased (essentially unbiased) and more precise than when foreign shocks

\footnotetext{
${ }^{20}$ Faust and Leeper [1997] argue that structural VARs with long-run restriction do not enable precise inference. As large as confidence interval may seem in Figure 3, inference is precise enough here to mistakingly reject that employment increases on impact.

${ }^{21}$ Notice that employment enters the VAR as first-difference, while stationary in the theoretical model. Labour input is subject to the over-differenciation emphasized in Christiano et al. [2003] and Christiano, Eichenbaum and Vigfusson [2004]. Nevertheless, the structural VAR with long-run restriction of this experiment estimates consistently the model response of employment. This suggest that the relative volatility of the different shocks hitting the economy may matter more than the low-frequency properties of labour input.
} 
Figure 4: Estimated response of employment without foreign shocks
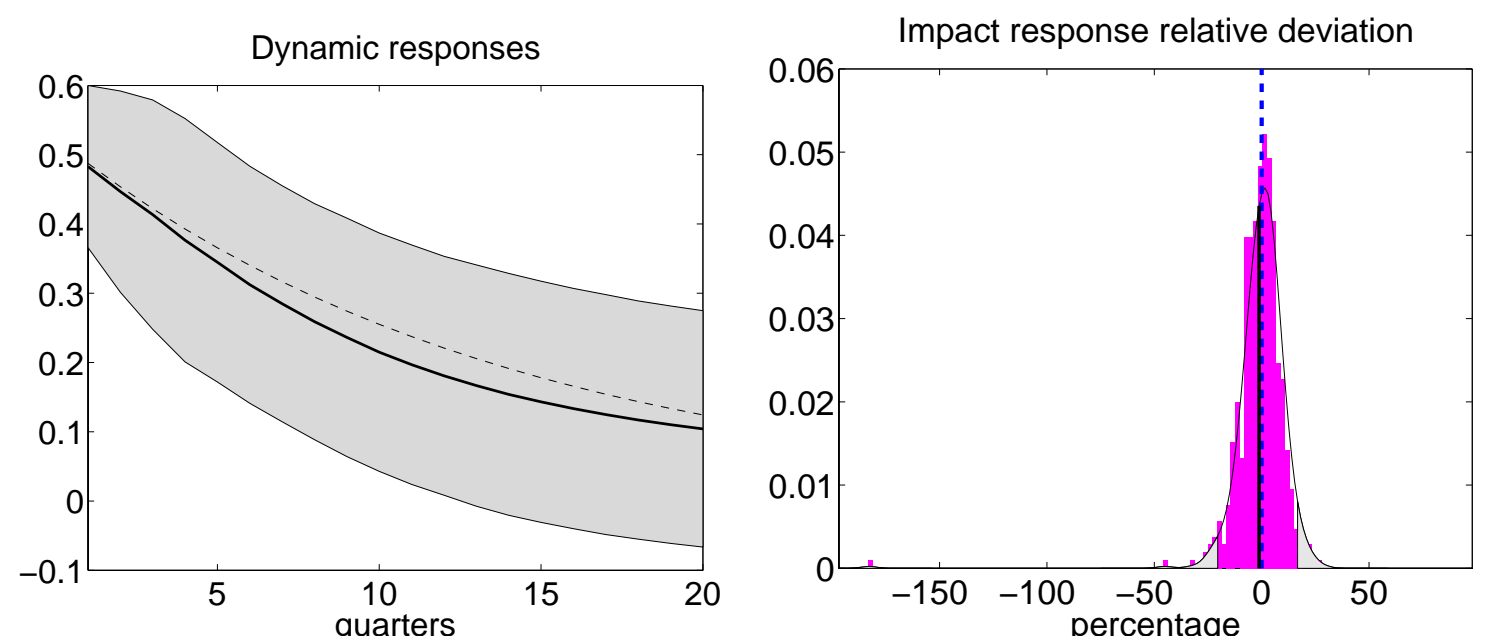

Note: VAR estimated on data generated by the international model with parameter values described in Table 4 ( $S=500$ simulations of 100 observations long samples), yielding the VMA representation (8).

were hitting the economy, as exemplified by the distribution of relative deviation on impact plotted in the right panel. In fact, measurement is doubly enhanced here. First, the permanent shock (which hits the common component of TFP) is now by far the most volatile one, while the volatility of the foreign shock largely prevails in the overall economy. Second, the two remaining shocks (the permanent shock to TFP common to both countries and the temporary shock to domestic TFP) have the same qualitative impact on domestic employment: a positive one. The average SVAR estimated response, which lies between the impact response to the permanent productivity shock and to the stationary productivity shock, is therefore less distorted.

The stationary shock to foreign TFP does induce a persistant increase of home labour productivity but a decrease of home employment. ${ }^{22}$ This shock is more volatile than the permanent one, when the domestic stationary shock is shut down (Figure 5) as well as in the initial economy. Hence, the estimated SVAR response of employment (see the left panel) does not differ much whether domestic shocks are present or not. The true impact response remains heavily underestimated, as is apparent in the right panel. Once again, the estimated impact is comprised between the true impact of the common shock and the impact of the foreign shock.

Figure 6 graphs the results of a final experiment with less persistent stationary shocks. Precisely, the autoregressive coefficient of the country-specific components of TFP, $\rho$, is set to

\footnotetext{
${ }^{22}$ As soon as returns to labour input are decreasing, any shock that decreases employment induces an increase in labour productivity, and therefore yields the same identification problems. Erceg et al. [2004] emphasize a preference shock and a shock to labour tax rates. All these shocks are labour wedges, in the terminology of Chari, Kehoe and McGrattan [2003].
} 
Figure 5: Estimated response of employment without domestic shocks
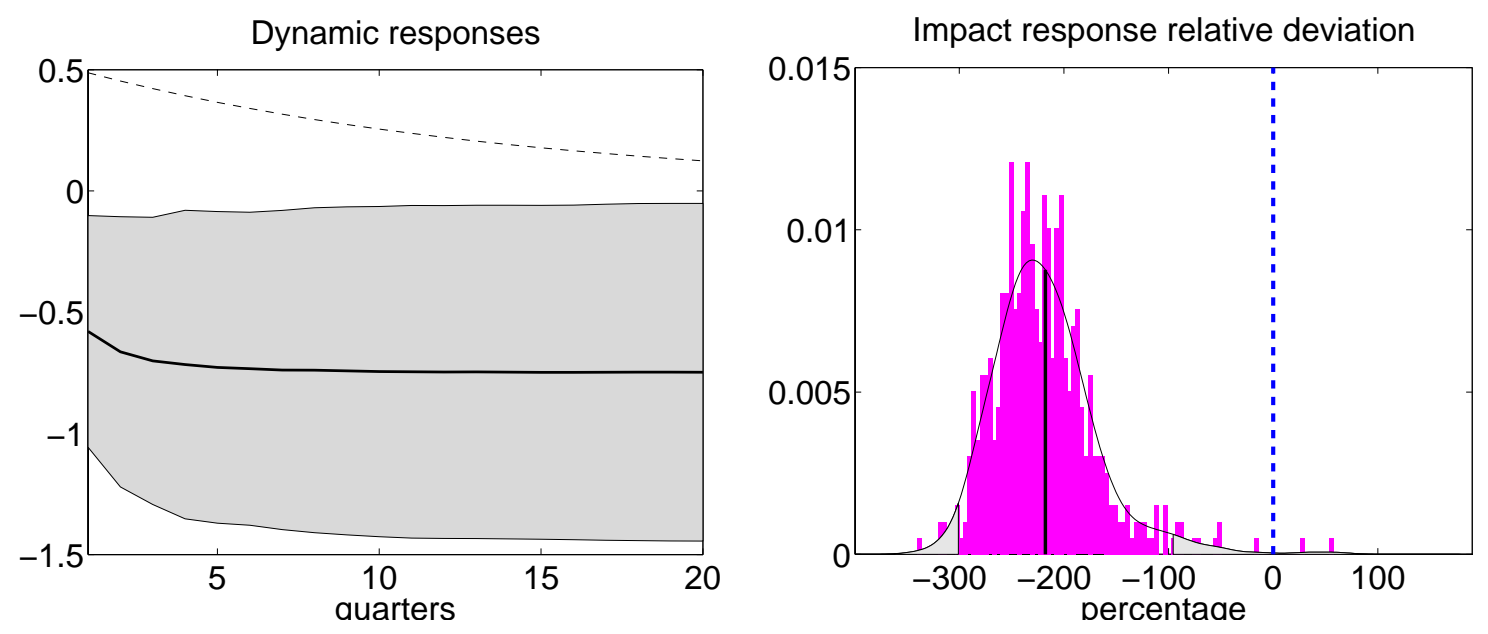

Note: VAR estimated on data generated by the international model with parameter values described in Table 4 ( $S=500$ simulations of 100 observations long samples), yielding the VMA representation (8).

half of the initial value $0.96 / 2$. For this parametrization, the shocks to domestic and foreign TFP have shorter-lived effects on domestic labour productivity. Hence, identification problems are milder, as witnessed in the left panel of Figure 6. The average estimated response of employment is no longer significantly negative at any horizon. Since the confidence interval is large, it contains the true value of $N_{1}(0)$ from the third period on. On impact, as displayed in the right panel, $97.20 \%$ of observations underestimate the true effect, but only $44.13 \%$ of them are now wrongly signed.

Figure 6: Estimated response of employment when stationary shocks are half as persistent
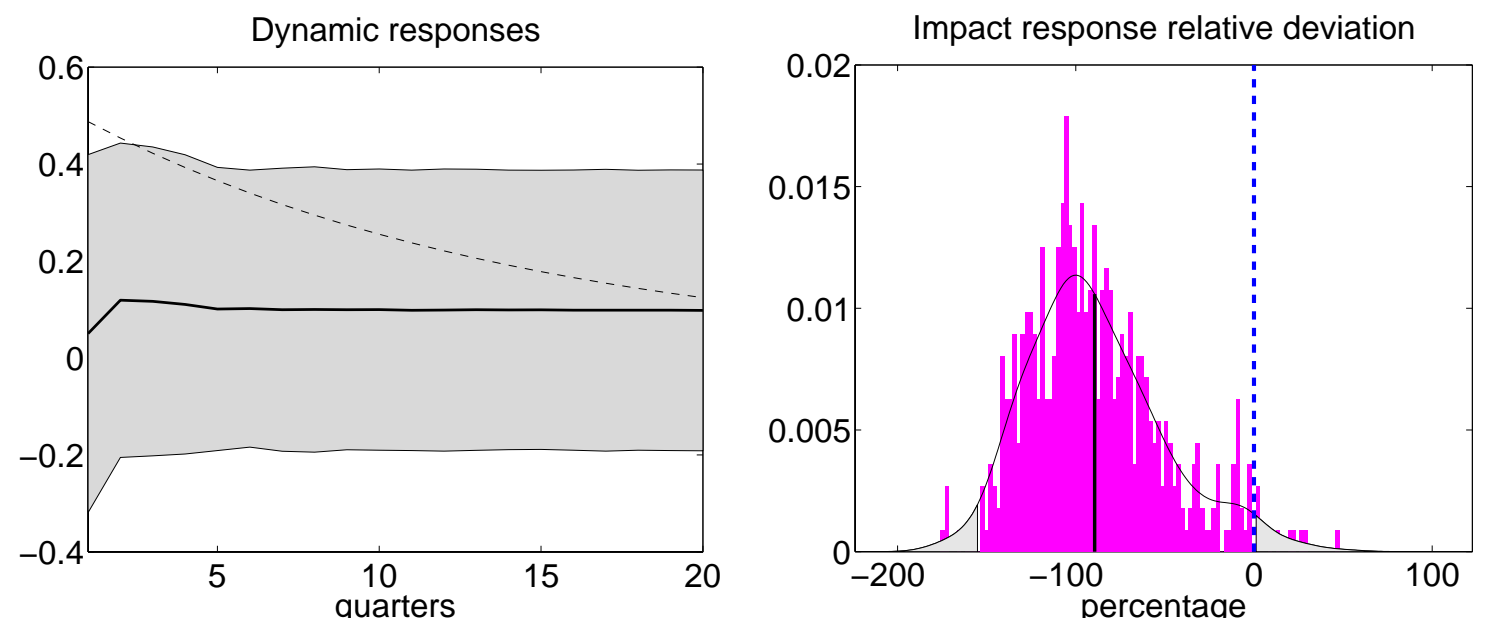

Note: VAR estimated on data generated by the international model with parameter values described in Table 4 ( $S=500$ simulations of 100 observations long samples), yielding the VMA representation (8). 
Generally speaking, the SVAR methodology suggested by Galí [1999] only delivers a reliable measure of the effects of permanent technology shocks on labour input when the economy is not hit by other shocks having long-lasting effects on labour productivity. In our model economy, this situation arises when $i$ ) the volatility of country-specific shocks is low relative to that of the aggregate shock; ii) country-specific shocks exhibit low levels of serial correlation; iii) the domestic economy constitutes a very large share of world population; or iv) asset portfolios exhibit no international diversification. None of these special cases seem particularly relevant to the current situation of the major seven countries.

In what follows, we will propose other setups to evaluate the short-run response of labour input to permanent technology shocks, and evaluate their relevance over artificial data. To make this test as demanding as possible, we retain the assumption of complete financial markets, for which contamination is the highest.

\subsection{Identification under aggregation}

So far, we have shown that structural VARs with long-run restriction applied on single-country data were providing biased estimates of the response of labour input to a permanent productivity shock. In light of this, the empirical evidence on individual G7 countries presented in Table 1 is highly questionable. In particular, the weighted sum of impact response of national employments (which is negative in our application) is not a reliable estimator of the effects of a permanent technology shock on G7 employment. We now investigate SVAR evaluation on aggregate data, using our model economy.

In the model, multinational aggregation is very easy. Labour input is homogeneous, so employment per capita in the overall economy (labeled hereafter 'zone') writes $n_{t}^{\text {zone }}=\pi_{1} n_{t}^{1}+$ $\left(1-\pi_{1}\right) n_{t}^{2}$. Furthermore, all firms produce an identical good, so that zone output per capita is

$y_{t}^{\text {zone }}=\pi_{1} y_{t}^{1}+\left(1-\pi_{1}\right) y_{t}^{2}$ and computing the average labour productivity in the zone composed of the two countries is straightforward.

Impulse response functions of zone labour input and productivity are plotted in Figure 7 (these graphs are the zone counterpart of Figure 2). Looking at the left panel, we remark that the response to the permanent TFP shock is exactly identical to the response of the home economy. This reflects the fact that this shock is common to both countries, and that its effects are identical in the two economies.

The country-specific stationary shock to home TFP (middle panel) induces an increase in zone labour input and labour productivity. The qualitative effects are the same here than over 
Figure 7: Theoretical impulse response functions of zone employment and labour productivity
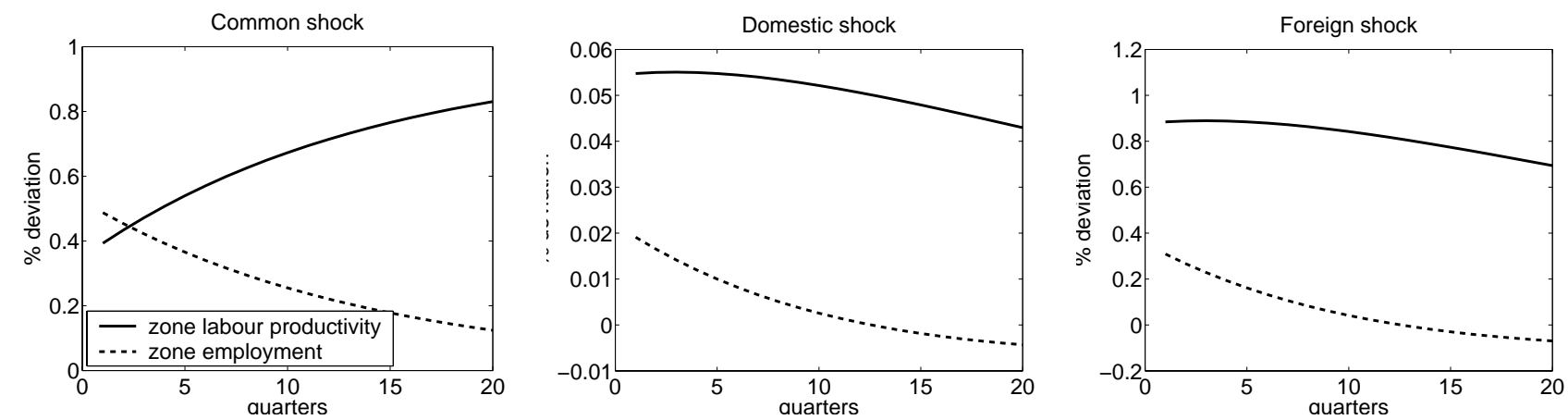

home economy alone. However, the quantitative impact on zone employment is much lower than on home employment, because this shock does decrease foreign employment. ${ }^{23}$

Regarding the stationary shock to foreign TFP (right panel), the same kind of averaging applies. After this shock, labour productivity rises in both countries, as emphasized in section 2.2, hence labour productivity rises at the aggregate level. On the contrary, the effects of the foreign shock on home and foreign employment are of opposite signs. Here, aggregate employment increases because the favorable effect on foreign employment exceeds the detrimental impact on home employment.

The following structural VMA evaluates the effects on zone employment of a permanent shock to zone labour productivity (for simplification, the draw indicator $k$ is removed now on):

$$
\left[\begin{array}{c}
\Delta x_{t}^{\text {zone }} \\
\Delta n_{t}^{\text {zone }}
\end{array}\right]=\left[\begin{array}{ll}
C_{11}(L) & C_{12}(L) \\
C_{21}(L) & C_{22}(L)
\end{array}\right] \epsilon_{t}^{\text {zone }}, \text { with } C_{12}(1)=0
$$

To test whether the SVAR specification (9) delivers a correct measure of the effects of the permanent technology shock, Figure 8 compares the estimated and true response of employment. The left panel shows that the sign of the estimated response of employment is reversed as compared to the estimates based only on the domestic economy. Qualitatively, the SVAR methodology delivers a correct evaluation when performed over aggregate data but an incorrect one when performed on single-country labour input and productivity. Quantitatively, the right panel of Figure 8 shows that the estimated impact response of employment is slightly underestimated ( $61.87 \%$ of observations underestimate the true value). Altogether, SVAR evaluation conducted on area data performs a lot better than its counterpart on national data.

\footnotetext{
${ }^{23}$ This is due to the favorable wealth effect on foreign households of the rise in domestic marginal productivity of capital.
} 
Figure 8: Estimated response of zone employment to the permanent zone productivity shock
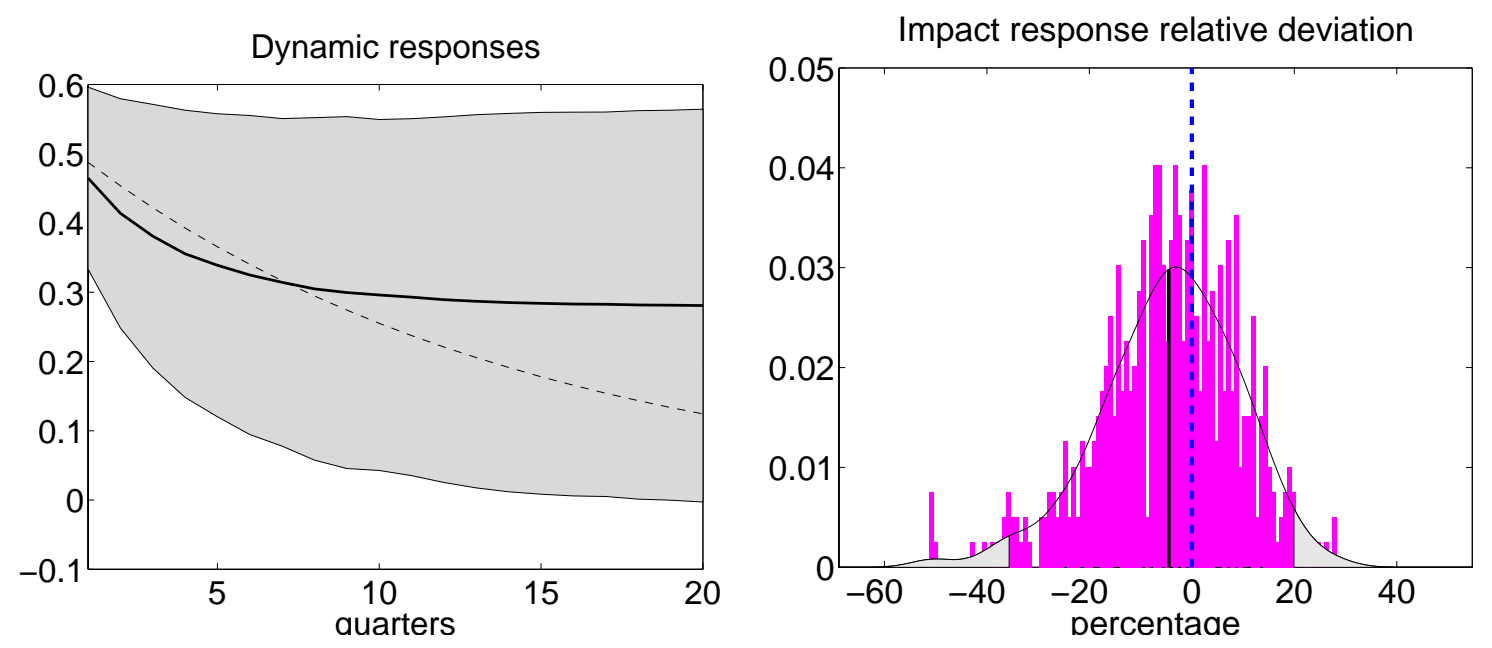

Note: VAR estimated on data generated by the international model with parameter values described in tables 4 ( $S=500$ simulations of 100 observations long samples), yielding the VMA representation (9).

\subsection{Application to aggregate data}

Through a multinational model economy, we have illustrated how the international propagation of productivity shocks could contaminate the measure of the technology effects on employment that SVAR models deliver. For a model economy calibrated to replicate key moments of the US economy, these biases are large enough to induce wrong inference. Even looking at data generated in an artificial world where exogenous changes in productivity stimulate labour input, one would conclude with great statistical confidence that labour input decreases after a permanent improvement in technology.

In a second step, we have shown that aggregation helped mitigate the identification problems. Intuitively, country-specific stationary shocks that contaminate the permanent technology shock tend to cancel out at the aggregate level.

The good news is that, at the aggregate/world level, ${ }^{24}$ this simple and attractive empirical procedure effectively discriminates between positive and detrimental effects on employment of technology shocks.

The bad news is that the bias is typically large for the US, the single largest existing economy. In other words, no single actual economy is large enough to be immune to the identification problems uncovered here. The zone experiment suggests, though, that aggregation of a set of countries may provide a reliable measure of the effects on world employment of a common permanent technology shock. OECD Main Economic Indicator dataset publishes data for three

\footnotetext{
${ }^{24}$ For the same reason, the measurement bias is also low in autarkic economies.
} 
groups of countries: Europe (European Union 15 countries or Euro area) ${ }^{25}$ G7, the group of major seven countries; and all OECD countries. The largest of these three groups is the last one. However, its composition has changed substantially as countries joined OECD (such as Korea, Hungary and Poland in 1996, both Czech and Slovak Republics...). To get the largest possible sample, we approximate the world economy by the G7. Even at the end of the sample, the G7 still accounts for $80 \%$ of real OECD GDP (and approximately for two thirds of world real GDP in 1995).

Figure 9: Impulse response function of G7 employment to a permanent shock to G7 average productivity of labour

Employment

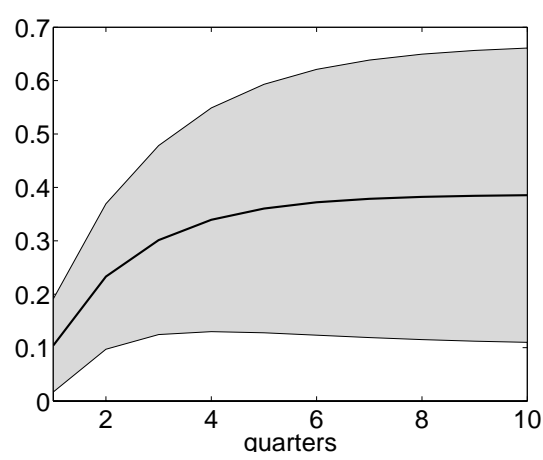

Labour productivity

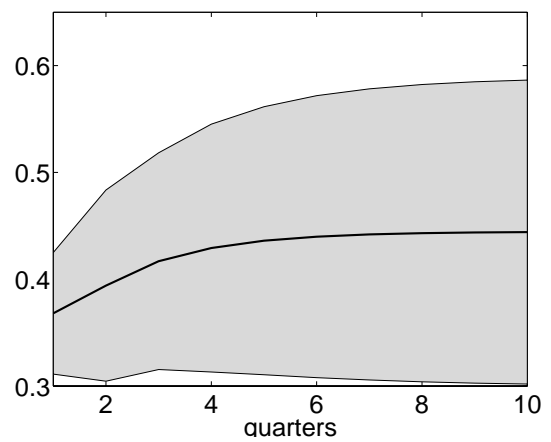

Figure 9 plots the impulse response of G7 employment and labour productivity to a permanent shock to G7 labour productivity. The left panel shows that G7 employment increases on impact after a permanent technology shock. ${ }^{26}$ Over time, the response of employment gets larger. The right panel displays the gradual increase of labour productivity, which is similar to the theoretical response (left panel in Figure 2). In the model economy, accumulation of capital was responsible for the gradual response of labour productivity.

Through the set of model-based experiments undertaken so far, SVAR evaluation carried over area data has proven much more reliable than SVAR evaluation carried over single-country data. These results are perfectly consistent with the aggregation puzzle apparent in Table 1 . The estimated effects of technology shocks on G7 employment differ from the weighted sum of national impacts because estimates on single-country data are biased, while area-wide estimates are not. In the data, the response of employment is lower at the country level than over the

\footnotetext{
${ }^{25}$ Galí [2004] uses data on the Euro area constructed at the European Central Bank. The results for this dataset are very similar to those found on US data, namely an average decrease in employment but with large confidence intervals which include zero.

${ }^{26}$ This is essentially the information carried in the last line of Table 1.
} 
entire zone, as predicted by the theoretical experiments.

\section{The effects of international technology shocks}

The previous section has shown that SVAR evaluation of the employment effects of technology shocks carried over individual countries are biased, while evaluation carried over internationally aggregated data are not. Here we investigate other identification methodologies in an international context.

\subsection{National data, aggregate data and long run restrictions}

In the model, the only permanent shock to home TFP affects TFP in both countries. Does the use of zone labour productivity instead of home labour productivity improve the reliability of SVAR evaluation when the long-run restriction is retained? To answer this question, we generate data through the process (6), compute the aggregate labour productivity, and finally estimate a VAR whose VMA representation is:

$$
\left[\begin{array}{c}
\Delta x_{t}^{\text {zone }} \\
\Delta n_{t}^{1}
\end{array}\right]=\left[\begin{array}{ll}
C_{11}(L) & C_{12}(L) \\
C_{21}(L) & C_{22}(L)
\end{array}\right] \epsilon_{t}, \text { with } C_{12}(1)=0 .
$$

Unfortunately, Figure 10 shows that this SVAR suffers from the same identification problem than Galí [1999]'s original specification. This in fact not surprising, since the three shocks have a long-lasting impact on zone labor productivity. Quantitatively, the bias is even larger because the foreign shocks has a greater positive impact on zone labor productivity (Figure 7) than on domestic labor productivity (Figure 2) - this is natural since it increases foreign average productivity of labour.

A somehow symmetrical experiment estimates the joint dynamic behaviour of home labour productivity and zone employment, yielding VMA representation (11):

$$
\left[\begin{array}{c}
\Delta x_{t}^{1} \\
\Delta n_{t}^{\text {zone }}
\end{array}\right]=\left[\begin{array}{ll}
C_{11}(L) & C_{12}(L) \\
C_{21}(L) & C_{22}(L)
\end{array}\right] \epsilon_{t}, \text { with } C_{12}(1)=0 .
$$

This specification evaluates the response of zone employment to a permanent shock to home labour productivity, displayed in Figure 11. The effects of the permanent productivity are precisely estimated in this setup, on impact as well as over a twenty period horizon. In fact, the existence of a balanced growth path restricts the permanent shock to TFP to be common to all countries. This means that, in the model, the permanent shock to home labour productivity and the permanent shock to zone labour productivity are identical. Hence, this specification delivers estimated effects which are very close to those of the zone SVAR specification (9), displayed in Figure 8. 
Figure 10: Estimated response of employment to the permanent zone productivity shock
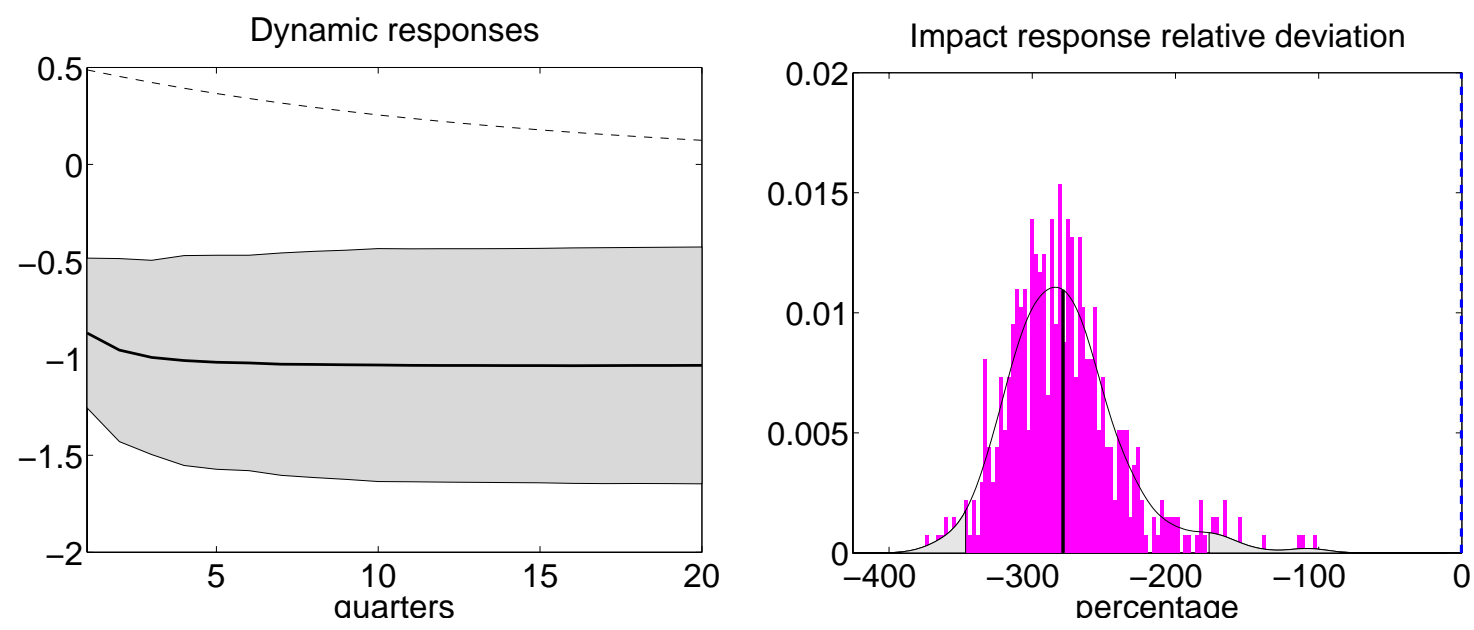

Note: VAR estimated on data generated by the international model with parameter values described in Table 4 ( $S=500$ simulations of 100 observations long samples), yielding the VMA representation (10).

Figure 11: Estimated response of zone employment to the permanent single-country productivity shock
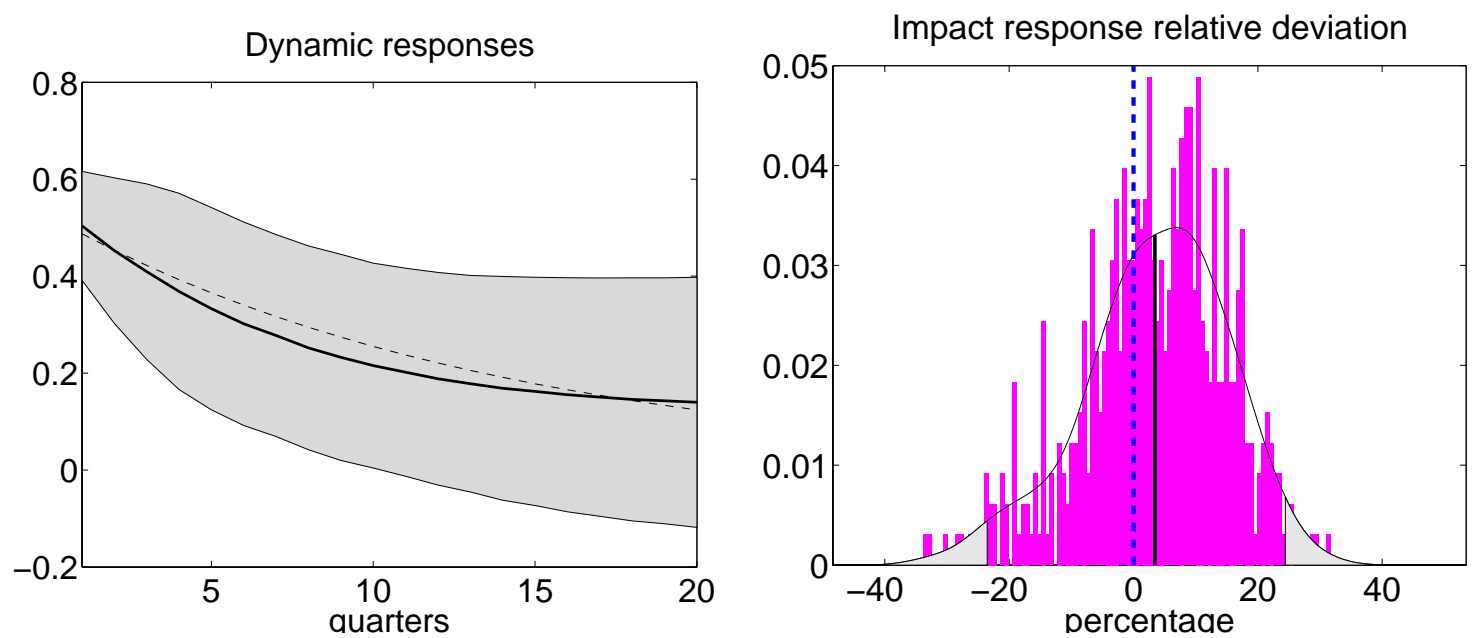

Note: VAR estimated on data generated by the international model with parameter values described in Table 4 ( $S=500$ simulations of 100 observations long samples), yielding the VMA representation (11). 
Figure 16 (in appendix) reports the estimated response of G7 employment to permanent shocks to labour productivity of each of the G7 countries, according to specification (11). ${ }^{27}$ Except for the United Kingdom, the estimated responses are close to each other, as predicted in the model economy. The overall pattern is an impact response close to zero, followed by a rise over time.

Specifications (9) and (11) deliver on artificial data unbiased estimates of the zone employment response to permanent productivity shocks, and therefore consistent evaluations of the impact of technology shocks on G7 employment. Our primary variable of interest is not aggregate employment though, but national employments.

\subsection{Identifying common shocks through short run restriction}

Galí [1999]'s setup relies on an identifying long-run restriction, namely that only technology shocks have permanent effects on labour productivity. As compared to Galí [1999]'s closed economy, our open economy model adds another restriction: permanent technology shocks hit all countries simultaneously and symmetrically (if several permanent technology shocks did coexist, no stationary world distribution of assets would exist). This additional restriction is empirically supported on G7 data (see Table 2). Hence, in a multinational framework, a permanent shock to productivity is a common one. This provides another restriction to identify technology shocks in actual data.

The existence of a common stochastic trend on (unobservable) TFPs drives predictions regarding national labor productivities, which are observable. The model implies that in all countries, and at the zone level, the average productivity of labour reacts symmetrically (see figures 2 and 7 ). Hence, the common permanent shock leaves productivity differentials unchanged on impact. ${ }^{28}$ This property has already been tested on actual data, and is not rejected in the G7. Accordingly, the evidence suggest that the only permanent shock hits the G7 countries symmetrically.

The additional restriction is a short-run one: on impact, the common permanent shock does not affect labour productivity differential. We use this short-run restriction in the following setup:

$$
\left[\begin{array}{c}
\Delta n_{t}^{1} \\
x_{t}^{1}-x_{t}^{\text {zone }}
\end{array}\right]=\left[\begin{array}{cc}
D_{11}(L) & D_{12}(L) \\
D_{21}(L) & D_{22}(L)
\end{array}\right] \epsilon_{t}, \text { with } D_{21}(0)=0
$$

\footnotetext{
${ }^{27}$ The last panel features specification (9), for comparison purpose.

${ }^{28}$ Over time, this differential might become positive or negative. This is for instance the case if capital adjustment costs differ across countries.
} 
The size of the test Figure 12 tests the SVAR representation with short-run restriction (12) over artificial data. The estimated impact response is essentially unbiased. This measurement scheme is immune to labour input overdifferenciation in the short-run, but not in the mediumrun. Labour input is stationary (though highly persistent) in the theoretical model, implying that its equilibrium path returns to steady-state. In VAR specification (12), on the contrary, labour input enters in first difference and does not exhibit mean-reversion. Qualitatively, the sign of the estimated response remains correct over the whole horizon.

Figure 12: Estimated response of domestic employment to the common shock
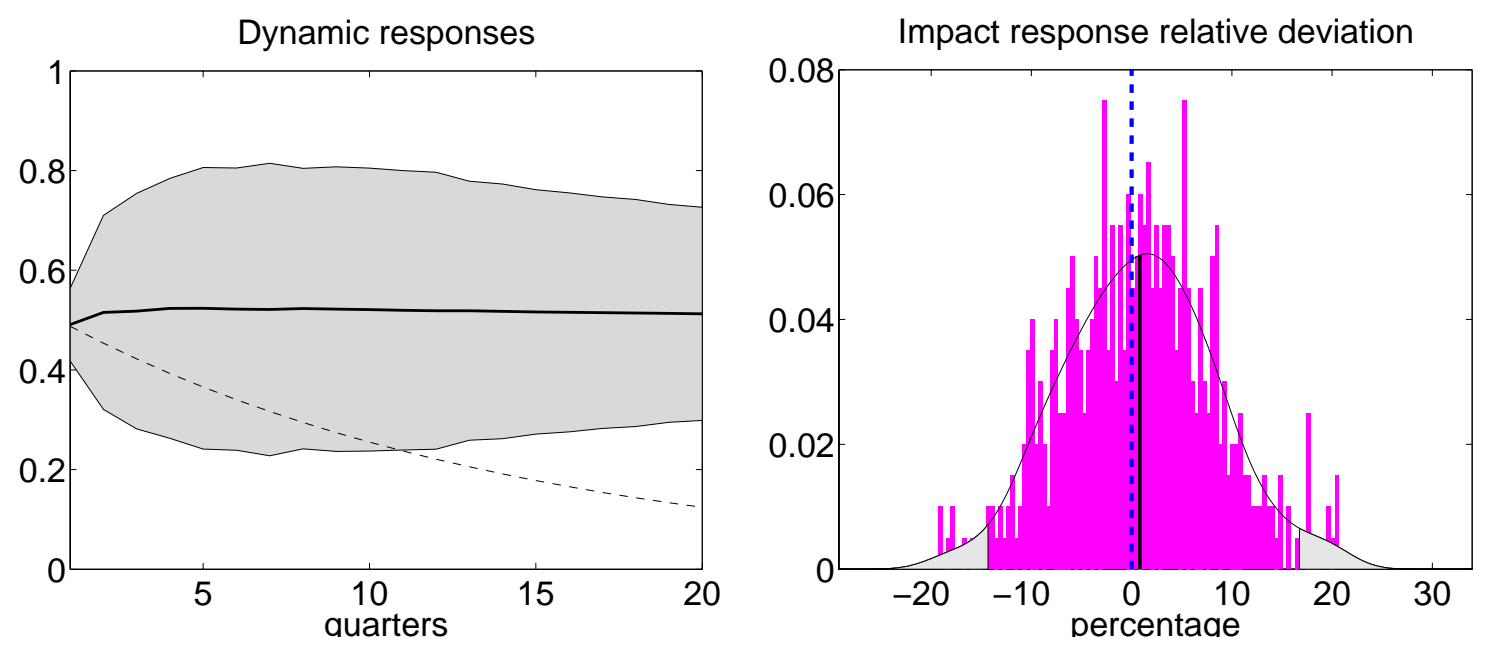

Note: VAR estimated on data generated by the international model with parameter values described in Table 4 ( $S=500$ simulations of 100 observations long samples), yielding the VMA representation (12).

In the model used to simulate artificial data, the only common shocks are the permanent ones. Under this assumption, the short-run restriction $D_{21}(0)=0$ used in specification (12) identifies precisely the permanent shocks to productivity, as Figure 12 makes clear. This shortrun identification scheme is also tested on a variant of the model with common non-permanent shocks. Precisely, a variant embeds the following variance-covariance matrix of shocks:

$$
\Sigma=\left(\begin{array}{ccc}
\sigma_{a}^{2} & 0 & 0 \\
0 & \sigma_{\varepsilon_{1}}^{2} & \tau \sigma_{\varepsilon_{1}} \sigma_{\varepsilon_{2}} \\
0 & \tau \sigma_{\varepsilon_{1}} \sigma_{\varepsilon_{2}} & \sigma_{\varepsilon_{2}}^{2}
\end{array}\right)
$$

with $\tau$ in $[0,1[$. When $\tau=0$, the only common shocks hitting the model economy are permanent (this is the case displayed in Figure 12). Otherwise, the correlation between the stationary shocks to home and foreign productivity equals $\tau$.

For increasing values of $\tau$, the average impact response of employment to the shock that does not affect relative labour productivity in the short-run is plotted in Figure 13. This number 
(thick solid line) is nearly not affected by the degree of correlation between the stationary shocks. The true impact response of labour input to common permanent technology shock being insensitive to this correlation, we can conclude that the short-run restriction delivers consistent estimates whatever the correlation structure. Remark that long-run restriction with zone data (thick dotted line) delivers similar results, but only at the aggregate level. Finally, the impact response obtained through long-run restriction with single-country data (thin solid line) is heavily downward biased for any value of the correlation between stationary shocks.

Figure 13: Estimated average impact response of domestic employment to the common shock

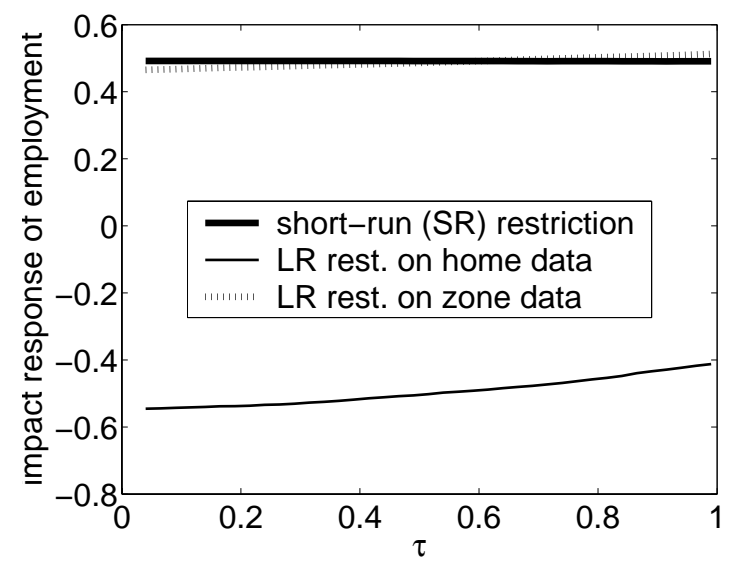

Note: VAR estimated on data generated by the international model with parameter values described in Table 4 and with the stochastic structure (13) ( $S=500$ simulations of 100 observations long samples). The 'short-run restriction' experiment refers to VAR specification (12); experiment 'long-run restriction with home data' refers to VAR specification (8); and experiment 'long-run restriction with zone data' refers to VAR specification (9).

The power of the test The last two experiments show that the SVAR with short-run restriction underlying specification (12) accurately measures an impact increase of employment in an experimental world where technology shocks improve labour input. But this measurement setup is only informative if it also detects decreases in labour input.

To perform this test, we conduct the following counterfactual experiment. The multinational model is now augmented with habit persistence on consumption. Specifically, the alternative momentary utility of writes $\log \left(C_{t}-b \bar{C}_{t-1}\right)+\vartheta \log L_{t}$, where $C_{t}$ denotes individual consumption and $\bar{C}_{t}$ aggregate consumption. Following Fuhrer [2000], $b$ is set to .8.

This utility function exacerbates consumption smoothing. Francis and Ramey [2005a] and Wen [2001] combine habit persistence with capital adjustment costs. In their setup, both consumption and investment are sluggish. Hence, output does not increase much after a permanent 
improvement in technology and technology shocks have detrimental effects on labour input.

Figure 14: Estimated response of domestic employment to the common shock under habit persistence
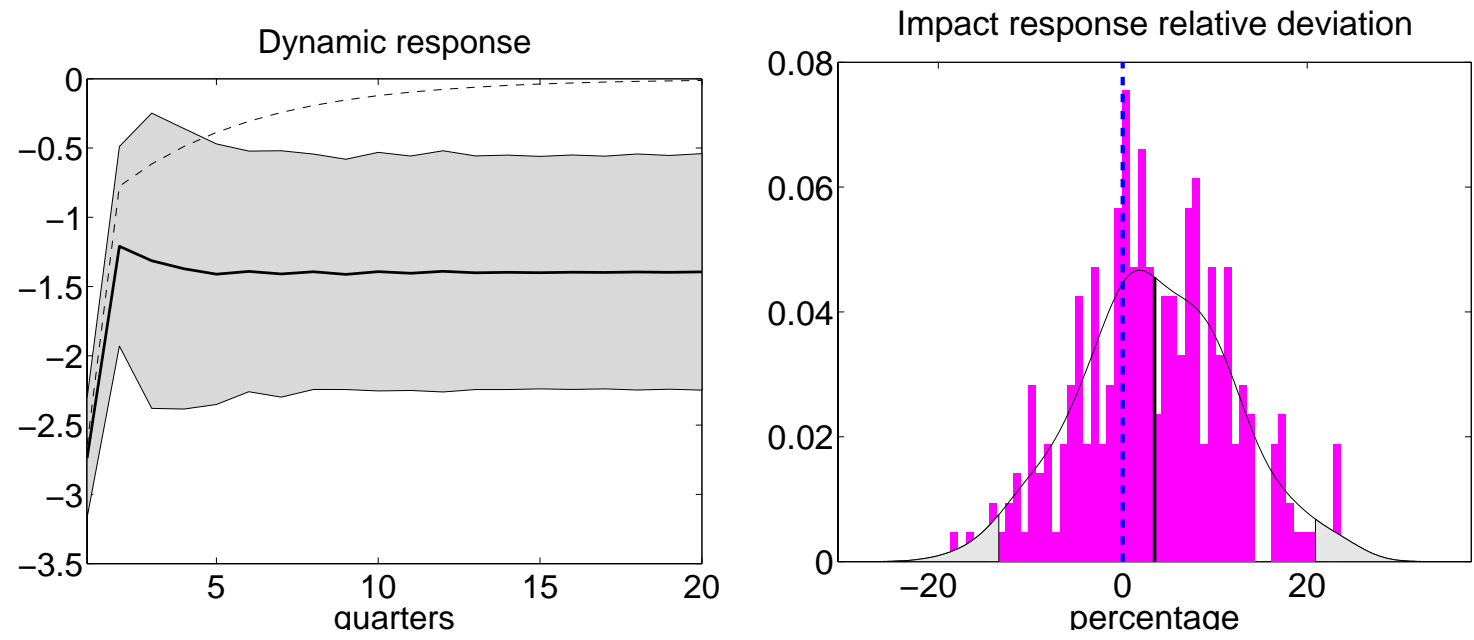

Note: VAR estimated on data generated by the international model augmented with habit persistence and with parameter values described in Table 4 ( $S=500$ simulations of 100 observations long samples), yielding the VMA representation (12).

The theoretical impulse response function of labour input to the permanent productivity shock is displayed as the dashed line of Figure 14. The large negative impact of technology shocks on labour input is well captured by the SVAR with short-run restriction. Hence, a test based on this SVAR evaluation has discriminating power against this specific alternative model.

With this version of the model as with the first one, the estimated response is biased in the medium-run, because of overdifferenciation of labour input. This bias is however not large enough to reverse the sign of the estimated response.

\subsection{Application to G7 data}

The model-based experiments described above ensures that specification (12) consistently measures the short-run effects (up to one year or two) of common permanent productivity shocks on employment, regardless of the actual response. It therefore constitutes an informative device to evaluate how employment has historically been affected in the major seven countries by the common permanent shock to productivity.

Figure 15 reports the estimated impulse response function of employment to common shocks to labour productivity in each of the G7 countries, according to specification (12). In the seven countries, the impact response is positive: employment does not decrease on in the short-run in any country. 
Figure 15: Response of single-country employment to common shocks

United States

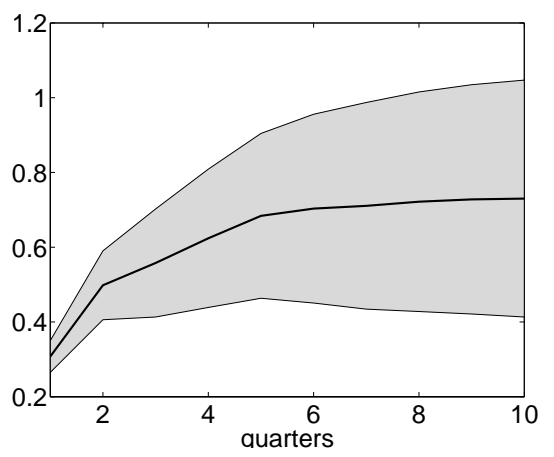

United Kingdom

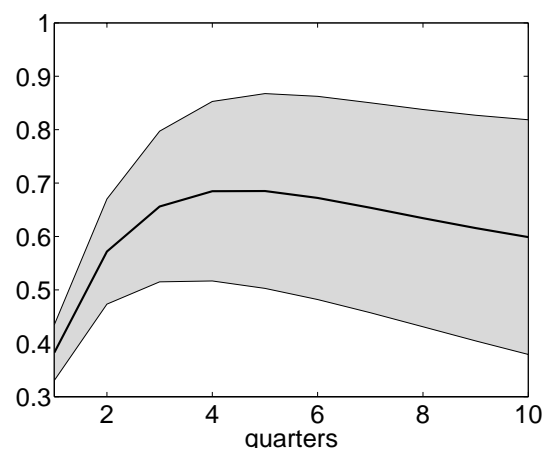

France

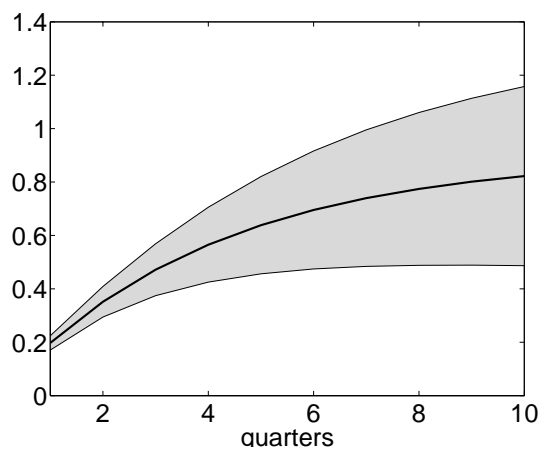

Japan

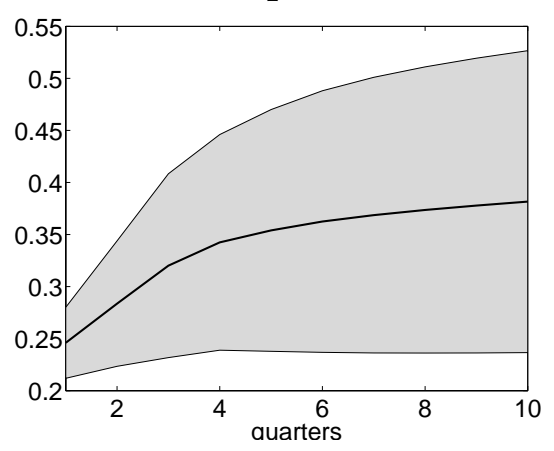

Canada

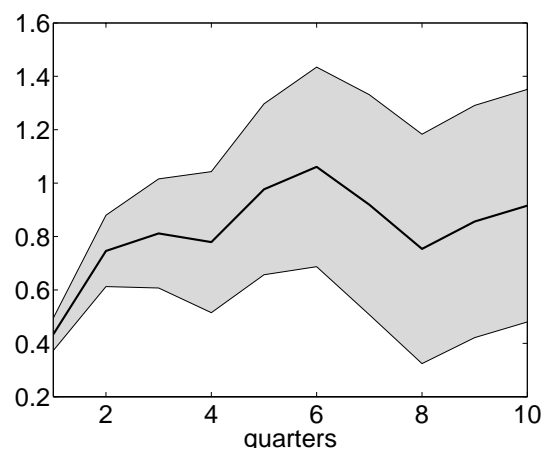

Germany

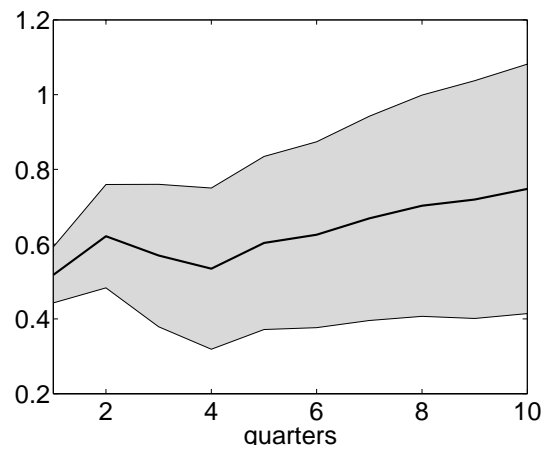

Italy

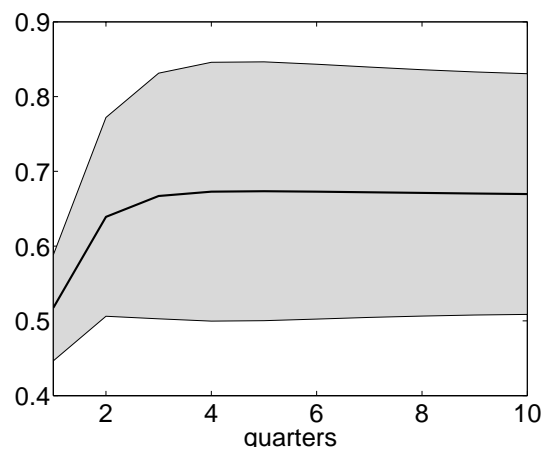

Note: VAR estimated on actual data, with the number of lags in Table 13. Sample period: 1978:1-2003:4. Source: OECD Main Economic Indicators. 
Over the first year, the rise in employment tends to increase. Over a longer horizon, employment exhibits sizeable mean-reversion in the United Kingdom but not in the six other countries. However, Figures 12 and 14 shows that mean-reversion of labour input is poorly accounted for by specification (12).

Testing the restrictions The SVAR underlying specification (12) measures the effects of common shocks to productivity. These measures can be compared to those of the effects of a permanent shock to productivity, delivered by the SVAR with long-run restriction (8), if the following two conditions are verified:

First, only the permanent shocks are common to the G7 countries. The estimation of SVAR specification (4) on actual data has already shown that the non-permanent shocks have significative impacts on productivity differentials in most countries (see Table 3), two potential exceptions being Canada and France. In this experiment, the long-run restriction is imposed for identification purpose and the short-run restriction is tested.

Second, country-specific shocks are not permanent. We now investigate whether this condition holds over actual G7 data: Is the common technology shock the unique permanent disturbance hitting the G7?

To test whether country-specific permanent productivity shocks exist, on top of the common ones, we use one more time a structural VAR with the growth rate of productivity and the productivity differential with respect to the G7. In line with the evidence in Table 2 and Figure 12 , we identify the common shock as the one that has no instantaneous impact on productivity differential.

$$
\left[\begin{array}{c}
\Delta x_{t} \\
x_{t}-x_{t}^{\mathrm{G} 7}
\end{array}\right]=\left[\begin{array}{cc}
\tilde{D}_{11}(L) & \tilde{D}_{12}(L) \\
\tilde{D}_{21}(L) & \tilde{D}_{22}(L)
\end{array}\right] \epsilon_{t}, \text { with } \tilde{D}_{21}(0)=0
$$

Given this identification scheme, the long-run effect on the country-specific (non-common) shock on labor productivity equals $\tilde{D}_{12}(1)$. Hence, the short-run restriction is imposed for identification purpose and the long-run restriction is tested: do country-specific shocks have permanent effects on labour productivities?

The responses after a hundred quarters for the seven countries are reported in Table 6 . Point estimates are positive in some countries (four) and negative in others (three), but are not significantly different from 0 at conventional levels. This shows that country-specific shocks have no permanent effects on labour productivity in the major seven countries, or equivalently that the common technology shock is the unique permanent shock on labour productivity.

In the two above-mentioned experiments, we have rejected the existence of country-specific permanent shocks and common temporary shocks on labour productivity of G7 countries. Ac- 
Table 6: 100-quarters response of relative labour productivity to a permanent productivity shock

\begin{tabular}{lrr}
\hline \hline country & point estimate & \% of distribution $\geq 0$ \\
\hline United States & 0.100 & 69.73 \\
Canada & 0.049 & 49.46 \\
United Kingdom & 0.201 & 94.64 \\
Germany & -0.099 & 34.31 \\
France & 0.717 & 67.32 \\
Italy & -0.270 & 14.17 \\
Japan & -0.176 & 17.47 \\
\hline \hline
\end{tabular}

Note: VAR estimated on actual data, with the number of lags in Table 13. The estimated density function over $S=500$ simulations is smoothed with a Gaussian kernel. Sample period: 1978:1-2003:4. Source: OECD Main Economic Indicators.

cording to these results, G7 countries receive one permanent common shock and several countryspecific temporary shock, which is precisely the stochastic structure embed in the DSGE model we use to simulate artificial data.

Moreover, this confirms that the VAR with long-run restriction (2) used, among others, by Galí [1999] and Francis and Ramey [2005a], is meant to identify the same shock as the VAR with short-run restriction underlying specification (12). Still, these two procedures yield highly different results over actual data as well as over artificial data, generated for experiment purpose. Having observed the sharp contrast in performance of the two measurement schemes over experimental data (see Figures 3 and 12 respectively), it is in fact not surprising that the evaluations they provide over actual data differ that much.

Overall, these results contradict the detrimental effects on employment of permanent technology shocks put forward by Galí [1999], Galí and Rabanal [2004], Francis and Ramey [2005a] and Francis and Ramey [2005b]. Although the mapping between price rigidity and the shortrun response of employment to technology shocks is not clear-cut, this paper casts reasonable doubt on the empirical evidence used to dismiss the Real Business Cycle literature.

\section{Conclusion}

This paper belongs to the growing literature evaluating the empirical effects of technology shocks on employment using VAR specifications. The aim of this literature is to establish a robust stylized fact which would discriminate between competing business cycle models.

From a methodological point of view, evaluations carried over using VARs are informative and useful if they provide reliable measures of the 'true' evolution of employment. We argue 
that existing VARs do not meet this requirement. Our claim is based on both empirical and theoretical evidence. Empirically, the sign of the measured response of employment in the major seven countries is not invariant to aggregation. Theoretically, the measured response of employment significantly differs from the true one when data are generated with a model which replicates a number of US business cycle statistics. This measurement error stems from the use of labour productivity as a proxy for technology jointly with a long-run identifying restriction.

Using this multinational model as a guide, we propose a novel identification scheme. This alternative methodology combines data from various countries and makes use of a short-run identifying restriction, namely that technology shocks hit simultaneously and symmetrically the different economies. Over artificial data, this measurement device performs well in terms of size and of discriminating power: it reliably detects the short-run movements in employment, should the true movements be positive or negative.

An application over actual data suggests that employment does increase in the short-run after a common permanent technology shock, in the US as well as in the other G7 countries. This evidence, which contradicts existing empirical findings, does not favor the rejection of the whole class of flexible-price model in favour of sticky-price models.

The analysis undertaken in this paper emphasizes the international transmission of shocks. We believe that the empirical quest for the forces driving the business cycle should take into account such external shocks on top of domestic factors. 


\section{References}

Backus, D., P. Kehoe, and F. Kydland, International Real Business Cycles, Journal of Political Economy, August 1992, 100 (4), 745-775.

_ _ _ a , and _ International Business Cycles: theory versus evidence, in T.F. Cooley, editor, Frontiers of Business Cycle Research, Princeton University Press, 1995.

Baxter, M. and M. Crucini, Explaining saving investment correlation, American Economic Review, 1993, 83, 416-435.

Blanchard, O.J. and D. Quah, The dynamic effects of aggregate supply and demand disturbances, American Economic Review, September 1989, 79 (4), 655-673.

Bordo, M. D. and T. Helbling, Have national business cycles become more synchronized?, Working Paper 10130, NBER 2003.

Chari, V.V., P. J. Kehoe, and E. McGrattan, Business cycle accounting, Staff report 328, Federal Reserve Bank of Minneapolis 2003.

$\ldots$ _ _ , and _ _ An economic test of structural VAR, Working Paper 631, Federal Reserve Bank of Minneapolis 2004.

Christiano, L. J., M. Eichenbaum, and R. J. Vigfusson, What happens after a technology shock?, Working Paper 9819, NBER 2003.

$\ldots$ _ _ measures of technology, Journal of the European Economic Association, 2004, 2 (2-3), 381-395.

Collard, F. and H. Dellas, Technology shocks and employment, Discussion Paper 3680, CEPR 2003.

Cooley, T. and E. Prescott, Economic growth and business cycles, in T. Cooley, editor, Frontiers of Business Cycle Research, Princeton University Press, 1995, chapter 1.

Dupaigne, M., P. Fève, and J. Matheron, Technology shocks and employment: do we really need models with a fall in hours?, mimeo, GREMAQ \& Banque de France 2005.

Erceg, C., L. Guerrieri, and C. Gust, Can long-run restrictions identify technology shocks?, International Finance Discussion Papers 792, Board of Governors of the Federal Reserve System 2004.

Faust, J. and E.M. Leeper, When do long-run identifying restrictions give reliable results?, Journal of Business Economics and Statistics, 1997. 
Francis, N. R. and V. A. Ramey, Is the technology-driven Real Business Cycle hypothesis dead? Shocks and aggregate fluctuations revisited, Journal of Monetary Economics, 2005, forthcoming.

and __ , The source of historical economic fluctuations: an analysis using long-run restrictions, Journal of the European Economic Association, 2005, forthcoming.

, M. T. Owyang, and A. T. Theodrou, What explains the varying monetary response to technology shocks in G-7 countries?, Working Paper 2004-002C, The Federal Reserve Bank of St.Louis 2004.

Fuhrer, J. C., Habit formation in consumption and its implications for monetary-policy models, American Economic Review, 2000, 90 (3), 367-390.

Galí, J., Technology, employment and the business cycle: do technology shocks explain aggregate fluctuations?, American Economic Review, 1999, 89 (1), 249-271.

— - On the role of technology shocks as a source of business cycles: some new evidence, Journal of the European Economic Association, 2004, 2 (2-3), 372-380.

_, Trends in hours, balanced growth, and the role of technology in the business cycle, Working Paper 11130, NBER 2005.

_ model fit postwar US data?, NBER Macroeconomics Annual, 2004, forthcoming.

King, R.G., C.I. Plosser, J.H. Stock, and M.W. Watson, Stochastic trends and economic fluctuations, American Economic Review, 1991, 81 (4), 819-840.

Kose, A., C. Otrok, and C. H. Whiteman, International business cycles: world, region, and country-specific factors, American Economic Review, 2003, 93 (4), 1216-1239.

Levin, A., C. F. Lin, and C. S. J Chu, Unit root test in panel data: asymptotic and finite sample properties, Journal of Econometrics, 2002, 108.

Moon, H. R. and B. Perron, Testing for a unit root in panels with dynamic Factors, Journal of Econometrics, 2004, 122.

Stock, J. H. and M. W. Watson, Understanding changes in international business cycle dynamics, Working Paper 9859, NBER 2003.

Uhlig, H., Do technology shocks lead to a fall in total hours worked?, Journal of the European Economic Association, 2004, 2 (2-3), 361-371. 
Wen, Y., Technology, employment and the business cycle: do technology shocks explain aggregate fluctuations? Comment, Working Paper 01-19, Center for Analytic Economics, Cornell University 2001.

\section{Appendix}

\section{A Univariate unit root tests}

Tables 7 to 9 report the results of augmented Dickey-Fuller unit root and KPSS stationarity tests over the average productivity of labour (APL), employment and their growth rates in each of the major seven countries.

Table 7: ADF unit root tests on average labour productivity (APL) and employment

\begin{tabular}{lrrrrrrrr}
\hline \hline & \multicolumn{2}{c}{ log-level } & \multicolumn{2}{c}{ critical values } & \multicolumn{2}{c}{ difference } & \multicolumn{2}{c}{ critical values } \\
\cline { 7 - 9 } country & APL & empl. & $1 \%$ & $5 \%$ & APL & empl. & $1 \%$ & $5 \%$ \\
\hline United States & -3.366 & -0.341 & -4.005 & -3.461 & -10.824 & -3.713 & -3.439 & -2.915 \\
Canada & -2.534 & -1.153 & -4.005 & -3.461 & -9.478 & -2.706 & -3.439 & -2.915 \\
United-Kingdom & -2.524 & -3.437 & -4.005 & -3.461 & -9.522 & -6.059 & -3.439 & -2.915 \\
Germany & -4.491 & -2.344 & -4.005 & -3.461 & -12.035 & -6.789 & -3.439 & -2.915 \\
France & 0.055 & -2.393 & -4.005 & -3.461 & -10.830 & -4.119 & -3.439 & -2.915 \\
Italy & -0.478 & -0.839 & -4.005 & -3.461 & -10.283 & -7.438 & -3.439 & -2.915 \\
Japan & -1.470 & -1.699 & -4.005 & -3.461 & -10.557 & -8.423 & -3.439 & -2.915 \\
G7 & -2.821 & -2.346 & -4.005 & -3.461 & -10.328 & -4.864 & -3.439 & -2.915 \\
\hline \hline
\end{tabular}

Note: ADF $t$-statistics for the null hypothesis of a unit root in the log or growth rate of each time series, based on an ADF test with 8 lags, an intercept (and a time trend for log-level data). Sample period 1978:1-2003:4. Source OECD Main Economic Indicators.

ADF tests adopt the null hypothesis that data are difference-stationary. This null is not rejected at the $5 \%$ level for the employment of any country. Furthermore, the non-stationarity of employment growth rates is rejected at the $1 \%$ level in each country but Canada (for which it is rejected at the $10 \%$ level, the critical value being -2.588).

The weak power of ADF tests in small samples is a well-known issue. We also run KPSS tests, the null hypothesis of which is stationarity. When a time trend is included (Table 8), the stationarity of employment is rejected at the $5 \%$ level for three countries (France, Italy and Japan), and at the $10 \%$ level for three others (the United States, United Kingdom and Germany).

When only an intercept is included (Table 9), the stationarity of employment in the remaining country (Canada) is rejected at the $1 \%$ level, while it is rejected at the $5 \%$ level for G7 
Table 8: KPSS unit root tests on average labour productivity (APL) and employment

\begin{tabular}{lccrrrrrrrr}
\hline \hline & \multicolumn{2}{c}{ log-level } & \multicolumn{3}{c}{ critical values } & \multicolumn{3}{c}{ difference } & \multicolumn{3}{c}{ critical values } \\
\cline { 9 - 11 } country & APL & empl. & $1 \%$ & $5 \%$ & $10 \%$ & APL & empl. & $1 \%$ & $5 \%$ & $10 \%$ \\
\hline United States & 0.222 & 0.123 & 0.216 & 0.146 & 0.119 & 0.370 & 0.139 & 0.739 & 0.463 & 0.347 \\
Canada & 0.221 & 0.097 & 0.216 & 0.146 & 0.119 & 0.244 & 0.065 & 0.739 & 0.463 & 0.347 \\
United-Kingdom & 0.086 & 0.120 & 0.216 & 0.146 & 0.119 & 0.048 & 0.135 & 0.739 & 0.463 & 0.347 \\
Germany & 0.161 & 0.120 & 0.216 & 0.146 & 0.119 & 0.107 & 0.066 & 0.739 & 0.463 & 0.347 \\
France & 0.371 & 0.335 & 0.216 & 0.146 & 0.119 & 0.662 & 0.662 & 0.739 & 0.463 & 0.347 \\
Italy & 0.205 & 0.185 & 0.216 & 0.146 & 0.119 & 0.352 & 0.256 & 0.739 & 0.463 & 0.347 \\
Japan & 0.319 & 0.181 & 0.216 & 0.146 & 0.119 & 0.289 & 0.209 & 0.739 & 0.463 & 0.347 \\
G7 & 0.090 & 0.074 & 0.216 & 0.146 & 0.119 & 0.082 & 0.062 & 0.739 & 0.463 & 0.347 \\
\hline \hline
\end{tabular}

Note: KPSS statistics for the null hypothesis of no unit root in the log or growth rate of each time series, based on a test with bandwidth 6 including an intercept (and a time trend for log-level data). Sample period 1978:1-2003:4. Source OECD Main Economic Indicators.

Table 9: KPSS unit root tests on average labour productivity (APL) and employment without time trend

\begin{tabular}{lrrrrr}
\hline \hline & \multicolumn{2}{c}{ log-level } & \multicolumn{3}{c}{ critical values } \\
\cline { 4 - 6 } country & APL & empl. & $1 \%$ & $5 \%$ & $10 \%$ \\
\hline United States & 1.554 & 1.239 & 0.739 & 0.463 & 0.347 \\
Canada & 1.511 & 0.959 & 0.739 & 0.463 & 0.347 \\
United-Kingdom & 1.553 & 0.907 & 0.739 & 0.463 & 0.347 \\
Germany & 1.564 & 0.439 & 0.739 & 0.463 & 0.347 \\
France & 1.552 & 0.338 & 0.739 & 0.463 & 0.347 \\
Italy & 1.553 & 0.586 & 0.739 & 0.463 & 0.347 \\
Japan & 1.539 & 1.340 & 0.739 & 0.463 & 0.347 \\
G7 & 1.572 & 0.467 & 0.739 & 0.463 & 0.347 \\
\hline \hline
\end{tabular}

Note: KPSS statistics for the null hypothesis of no unit root in the log or growth rate of each time series, based on a test with bandwidth 6 including an intercept. Sample period 1978:1-2003:4. Source OECD Main Economic Indicators. 
aggregate data (this specification rejects the null hypothesis at the $10 \%$ level for all countries but France, where employment exhibits a strong downward trend).

The stationarity of the growth rates of employment is not rejected at the $5 \%$ level for all countries except France, for which it is not rejected at a $1 \%$ level.

The VMA representations (3) and (4) link the growth rate of productivity in each country with the productivity differentials vis-à-vis the United States or the G7, assuming that all those variables are stationary. Tables 10 and 11 present the stationarity tests of the productivity differential vis-à-vis the United States and the G7 respectively.

Table 10: Unit root tests on the labour productivity differential vis-à-vis the USA

\begin{tabular}{lrrrrrr}
\hline \hline & ADF & \multicolumn{2}{c}{ critical values } & KPSS & \multicolumn{2}{c}{ critical values } \\
country & $t$-stat. & $1 \%$ & $5 \%$ & stat & $1 \%$ & $5 \%$ \\
\hline Canada & -1.000 & -3.439 & -2.915 & 1.518 & 0.739 & 0.463 \\
United-Kingdom & -3.343 & -3.439 & -2.915 & 0.730 & 0.739 & 0.463 \\
Germany & -1.840 & -3.439 & -2.915 & 0.829 & 0.739 & 0.463 \\
France & -0.884 & -3.439 & -2.915 & 0.360 & 0.739 & 0.463 \\
Italy & -1.296 & -3.439 & -2.915 & 0.706 & 0.739 & 0.463 \\
Japan & -2.193 & -3.439 & -2.915 & 0.776 & 0.739 & 0.463 \\
\hline \hline
\end{tabular}

Note: ADF t-statistics for the null hypothesis of a unit root in the log or growth rate of each time series, based on an ADF test with 8 lags, intercept. KPSS statistics for the null hypothesis of no unit test with bandwidth 6, intercept. Sample period 1978:1-2003:4. Source OECD Main Economic Indicators.

Table 11: Unit root tests on the labour productivity differential vis-à-vis the G7

\begin{tabular}{lrrrrrrr}
\hline \hline & ADF & \multicolumn{2}{c}{ critical values } & KPSS & \multicolumn{2}{c}{ critical values } \\
country & t-stat. & $1 \%$ & $5 \%$ & stat & $1 \%$ & $5 \%$ \\
\hline United States & -2.397 & -3.439 & -2.915 & 0.966 & 0.739 & 0.463 \\
Canada & -1.365 & -3.439 & -2.915 & 1.455 & 0.739 & 0.463 \\
United-Kingdom & -3.191 & -3.439 & -2.915 & 0.143 & 0.739 & 0.463 \\
Germany & -2.829 & -3.439 & -2.915 & 0.346 & 0.739 & 0.463 \\
France & -0.057 & -3.439 & -2.915 & 0.718 & 0.739 & 0.463 \\
Italy & -1.442 & -3.439 & -2.915 & 0.434 & 0.739 & 0.463 \\
Japan & -2.230 & -3.439 & -2.915 & 0.657 & 0.739 & 0.463 \\
\hline \hline
\end{tabular}

Note: ADF $t$-statistics for the null hypothesis of a unit root in the log or growth rate of each time series, based on an ADF test with 8 lags, intercept. KPSS statistics for the null hypothesis of no unit test with bandwidth 6, intercept. Sample period 1978:1-2003:4. Source OECD Main Economic Indicators.

At the $5 \%$ level, the null hypothesis of non-stationarity of productivity differentials with 
respect to the US is only rejected by ADF tests for the United-Kingdom; but it is not rejected at the $1 \%$ level. On the contrary, KPSS tests reject stationarity at the $1 \%$ level in Canada and Germany, and at the $5 \%$ level for United Kingdom, Italy and Japan. The conclusions of both tests are therefore opposite for all countries but France.

Vis-à-vis the G7, the ADF tests reject unit root for United-Kingdom only, at the $5 \%$ level but not at the $1 \%$ level. The KPSS tests reject stationarity for the United States and Canada at the $1 \%$ level, as well as Japan and France at the $5 \%$ level. Hence, the results of these two sets of tests only coincide for the United-Kingdom, Germany, and Italy.

The weak small-sample power of unit root tests is well-known. Given the mixed results just reported, we also implement two of the panel unit root tests that have recently been proposed to overcome this lack of power.

\section{B Panel unit root tests}

Levin et al. [2002] propose a direct extension of time-series unit root tests to panel data. Their test is based on an estimation of:

$$
\Delta x_{i, t}=\rho x_{i, t-1}+\sum_{s=1}^{p_{i}} \gamma_{i, s} \Delta x_{i, t-s}+u_{i, t}, i=1, \ldots, N, t=1, \ldots, T
$$

where the error terms $u_{i, t}$ are independently distributed across individuals. This specification does not incorporate individual effects or time trends. Under the null hypothesis of a unit root (H0: $\rho=0$ ), the $t$-statistics is asymptotically normally distributed. In finite sample size, Levin et al. [2002] add a correction term. Levin et al. [2002] perform simulations for panels of 10 individuals and 25 dates, and the power of a 5\%-level test is as large as $99 \%$ (as compared to $27 \%$ for a univariate Dickey-Fuller test).

Moon and Perron [2004] release the assumption of independence between individuals. They first use a factor model, and test in a second step for the presence of a unit root over deviations from the factors. Their tests statistics are also based on the pooled estimate of the autoregressive term.

Table 12 presents the results of these two panel unit root tests over actual productivity differentials data. When productivity of the non-US countries are compared to the US one, Levin et al. [2002]'s test rejects the presence of a unit root at a 5\%; non-stationarity is rejected at the $1 \%$ level when productivity is the seven countries is compared to the G7 average.

Moon and Perron [2004] procedure does not identify any common factor (in both cases, as many factors as country are selected): the common forces underlying the evolution of labour productivity in the G7 countries are wiped out in productivity differentials. The non-stationarity 
Table 12: Panel unit root tests on the labour productivity differentials

\begin{tabular}{|c|c|c|c|c|c|c|}
\hline \multirow[b]{3}{*}{ test } & \multicolumn{3}{|c|}{ relative to the US } & \multicolumn{3}{|c|}{ relative to the G7 } \\
\hline & \multirow[b]{2}{*}{$t$-stat. } & \multicolumn{2}{|c|}{ critical values } & \multirow[b]{2}{*}{$t$-stat. } & \multicolumn{2}{|c|}{ critical values } \\
\hline & & $1 \%$ & $5 \%$ & & $1 \%$ & $5 \%$ \\
\hline Levin et al. [2002] & -1.992 & -2.326 & -1.645 & -2.374 & -2.326 & -1.645 \\
\hline Moon and Perron [2004] & -6.950 & -2.326 & -1.645 & -6.004 & -2.326 & -1.645 \\
\hline
\end{tabular}

Note: Statistics for the null hypothesis of a unit root. Sample period 1978:1-2003:4. Source OECD Main Economic Indicators.

of the deviations is rejected at the $1 \%$ level in both cases. The results we report use their preferred statistics $t_{b}$. Non-stationarity is also rejected when $t_{a}$ is used.

These results give support to the specification of VARs (3) and (4), as well as to the stochastic process of technology shocks employed in the theoretical model.

\section{Number of lags selected}

For each empirical experiment and each country, table 13 reports the number of lags chosen according to Akaïke's information criterion and likelihood ratio tests.

Table 13: Number of lags selected in each empirical application

\begin{tabular}{lrrrrr}
\hline \hline & $(\Delta x, \Delta n)$ & $\left(\Delta x, \Delta n^{\text {zone }}\right)$ & $\left(x-x^{\text {zone }}, \Delta n\right)$ & \multicolumn{2}{c}{$\left(\Delta x, x-x^{\text {zone }}\right)$} \\
\cline { 5 - 6 } restriction & long run & long run & long run & long run & short run \\
\hline United States & 12 & 2 & 3 & 2 & 2 \\
Canada & 7 & 4 & 5 & 4 & 4 \\
United-Kingdom & 9 & 1 & 1 & 7 & 7 \\
Germany & 1 & 1 & 6 & 6 & 1 \\
France & 3 & 1 & 1 & 1 & 1 \\
Italy & 1 & 1 & 1 & 1 & 1 \\
Japan & 4 & 1 & 2 & 1 & 1 \\
G7 & 1 & 1 & - & - & - \\
\hline \hline
\end{tabular}

\section{IRF of G7 employment to single-country permanent shocks}


Figure 16: Response of G7 employment to single-country permanent technology shocks
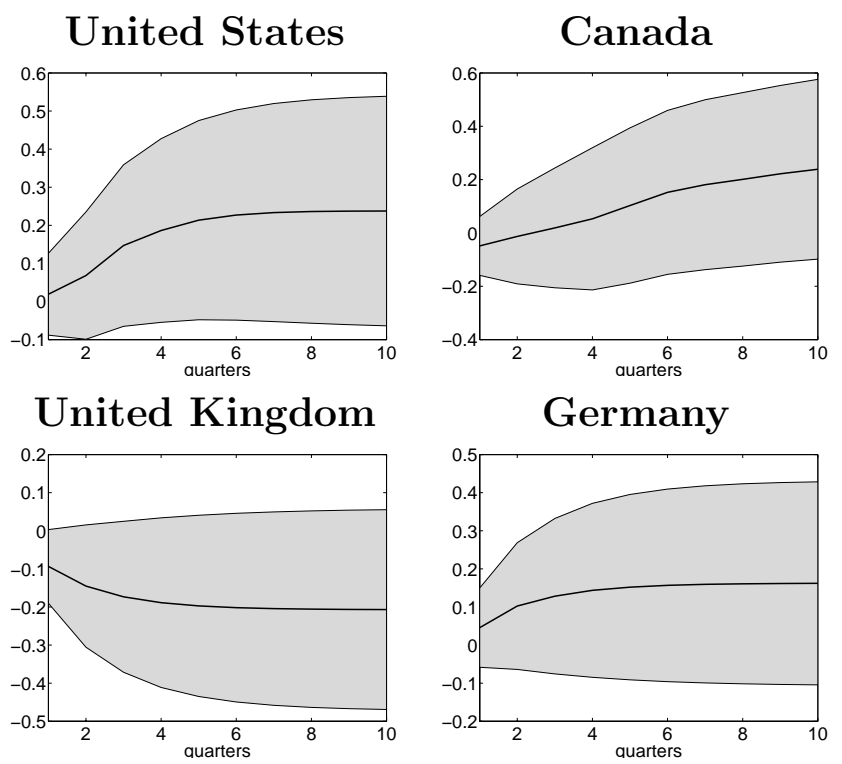

Italy
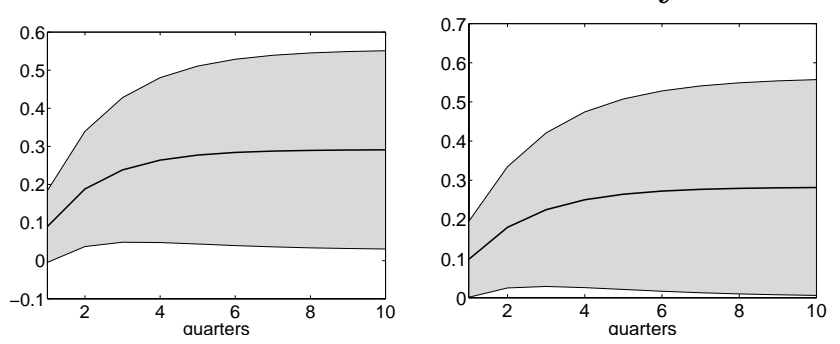

Japan
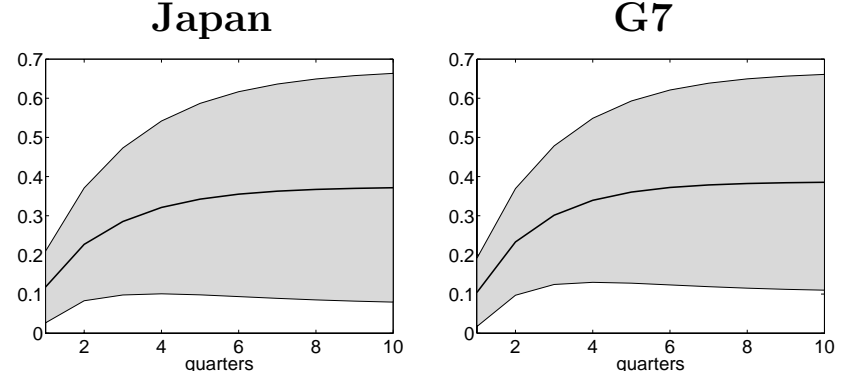

Note: VAR estimated on actual data, with the number of lags in table 13. Sample period: 1978:1-2003:4. Source: OECD Main Economic Indicators. 